AWARD NUMBER: W81XWH-13-1-0470

TITLE:

Identification and Targeting of Candidate Pre-Existing Lurker Cells that Give Rise to Castration-Resistant Prostate Cancer

PRINCIPAL INVESTIGATOR: Goldstein, Andrew

CONTRACTING ORGANIZATION:

University of California, Los Angeles

Los Angeles, CA 90095-1406

REPORT DATE: October 2014

TYPE OF REPORT: Annual Report

PREPARED FOR: U.S. Army Medical Research and Materiel Command Fort Detrick, Maryland 21702-5012

DISTRIBUTION STATEMENT: Approved for Public Release; Distribution Unlimited

The views, opinions and/or findings contained in this report are those of the author(s) and should not be construed as an official Department of the Army position, policy or decision unless so designated by other documentation. 


\section{REPORT DOCUMENTATION PAGE}

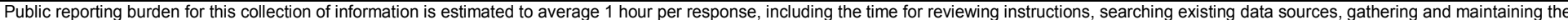

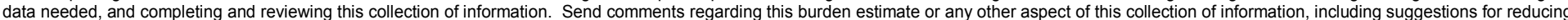

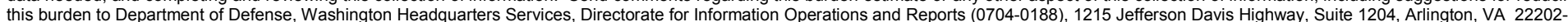

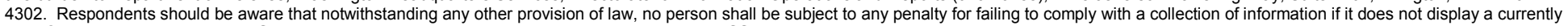
valid OMB control number. PLEASE DO NOT RETURN YOUR FORM TO THE ABOVE ADDRESS.
1. REPORT DATE
October 2014

4. TITLE AND SUBTITLE

Identification and Targeting of Candidate Pre-Existing Lurker Cells that Give Rise to Castration-Resistant Prostate Cancer
3. DATES COVERED

30 Sep 2013 - 29 Sep 2014

5a. CONTRACT NUMBER

5b. GRANT NUMBER

W81XWH-13-1-0470

5c. PROGRAM ELEMENT NUMBER

5d. PROJECT NUMBER

6. AUTHOR(S)

Goldstein, Andrew

E-Mail: AGoldstein@mednet.ucla.edu

7. PERFORMING ORGANIZATION NAME(S) AND ADDRESS(ES)

University of California, Los Angeles

Los Angeles, CA 90095-1406

9. SPONSORING I MONITORING AGENCY NAME(S) AND ADDRESS(ES)

10. SPONSOR/MONITOR'S ACRONYM(S)

U.S. Army Medical Research and Materiel Command

Fort Detrick, Maryland 21702-5012

12. DISTRIBUTION / AVAILABILITY STATEMENT

Approved for public release; distribution unlimited 5e. TASK NUMBER

5f. WORK UNIT NUMBER

8. PERFORMING ORGANIZATION REPORT NUMBER
11. SPONSOR/MONITOR'S REPORT NUMBER(S)

\section{SUPPLEMENTARY NOTES}

\section{ABSTRACT}

The purpose of this project is to evaluate the role of a rare subset of progenitor-like luminal cancer cells that may have special properties enabling them to resist standard therapies and mediate tumor recurrence. Our most significant accomplishment to date is identifying activated inflammatory signaling in these luminal progenitor cells. Blockade of this pathway depletes growth and survival of luminal progenitor cells by reducing expression of a number of important proliferative and anti-apoptotic factors including BCL2 and elF4E. Over-expression of elF4E, previously found to regulate luminal progenitor-like prostate cancer cells, can partially compensate for inhibition of NFkB signaling, suggesting that elF4E and NFkB are both regulators of this rare cell population and may act as part of the same signaling pathway. Further understanding of these progenitor cells, the pathways they use to control their growth and survival, and the markers they uniquely express will allow us to identify and target these cells in order to predict, prevent or treat advanced castration-resistant prostate cancer.

\section{SUBJECT TERMS}

Luminal progenitor, intermediate cell, lurker cell, Castration-resistant prostate cancer

\begin{tabular}{|c|c|c|c|c|c|}
\hline \multicolumn{3}{|c|}{ 16. SECURITY CLASSIFICATION OF: } & \multirow{2}{*}{$\begin{array}{l}\text { 17. LIMITATION } \\
\text { OF ABSTRACT } \\
\text { UU }\end{array}$} & \multirow{2}{*}{$\begin{array}{l}\text { 18. NUMBER } \\
\text { OF PAGES } \\
\qquad 20\end{array}$} & \multirow{2}{*}{$\begin{array}{l}\text { 19a. NAME OF RESPONSIBLE PERSON } \\
\text { USAMRMC } \\
\text { 19b. TELEPHONE NUMBER (include area } \\
\text { code) }\end{array}$} \\
\hline $\begin{array}{l}\text { a. REPORT } \\
\text { U }\end{array}$ & $\begin{array}{l}\text { b. ABSTRACT } \\
\text { U }\end{array}$ & $\begin{array}{l}\text { c. THIS PAGE } \\
\text { U }\end{array}$ & & & \\
\hline
\end{tabular}


TABLE OF CONTENTS

PAGE

1. INTRODUCTION 2

2. KEYWORDS 2

3. ACCOMPLISHMENTS 2

4. IMPACT 5

5. CHANGES/PROBLEMS

6. PRODUCTS 6

7. PARTICIPANTS \& OTHER COLLABORATING ORGANIZATIONS 7

8. SPECIAL REPORTING REQUIREMENTS

9. APPENDICES 


\section{INTRODUCTION}

Castration-resistant prostate cancer (CRPC) is a lethal disease. We lack standard biomarkers to predict hormonal sensitivity of tumors, and we need new targets for therapy to prevent or treat CRPC. The adaptation theory predicts that pre-existing androgen-independent prostate cancer cells (termed lurker cells) contribute to CRPC, as they are not targeted by androgen-deprivation therapy and may be capable of regenerating the tumor. Therefore, targeting these predicted lurker cells in combination with androgen-deprivation therapy would likely prevent or delay the onset of CRPC. The goals of this proposal are to provide functional evidence for intermediate luminal progenitor cells as the pre-existing "lurker" cells in primary prostate tumors, to evaluate potential therapeutic targets in intermediate luminal progenitor cells, and to define candidate biomarkers in intermediate luminal progenitor cells that can predict prognosis and response to hormonal therapy.

\section{KEYWORDS}

Prostate, epithelial, Androgen-deprivation therapy, Castration-resistant prostate cancer, luminal progenitor, intermediate cell, lurker cell

\section{ACCOMPLISHMENTS}

\section{What were the major goals of the project?}

Specific Aim 1. Interrogation of human I/LP cells as candidate lurker cells. Time frame: months 124. This Aim is 40-50\% complete as tumors have been initiated in Task 1 but further analysis will be collected in year 2 and a new approach will be added to Tasks 2 and 3 in year 2.

Task 1. Test the in vivo effects of castration on human luminal cancer subsets isolated from primary regenerated prostate tumors.

Task 2. Test the in vivo growth capacity of human luminal cancer subsets isolated from primary clinical prostate tumors.

Task 3. Test the in vivo effects of castration on human luminal cancer subsets isolated from primary clinical prostate tumors.

Specific Aim 2. Proof of principle therapeutic targeting of I/LP cells to prevent CRPC. Time frame: months 1-36. This aim is 25\% complete as data has been emerging from Tasks 4 and 5 .

Task 4. Determine if I/LP cancer cells from primary clinical human prostate tumors express genes associated with CRPC.

Task 5. Determine regulators of I/LP clonogenic activity in vitro.

Task 6. Target I/LP cells in vivo.

Specific Aim 3. Diagnostic potential of I/LP cells as lurker cells to predict CRPC development. Time frame: months 1-36. This aim is 33\% complete as Task 7 is accomplished while 8 and 9 will be performed in future years.

Task 7. Determine whether I/LP cell transcriptional signature can predict patient prognosis.

Task 8. Testing of candidate I/LP biomarkers on prostate cancer tissue.

Task 9. Determine if I/LP biomarkers can predict hormone sensitivity. 


\section{What was accomplished under these goals?}

\section{Specific Aim 1. Interrogation of human I/LP cells as candidate lurker cells.}

1) major activities: Experimental tumors were initiated using oncogenes Myc and myrAKT and propagating/fractionation studies have been initiated. In addition, new oncogene-driven models of human prostate cancer are being developed with different oncogene combinations that will allow us to determine if a range of human prostate tumors demonstrate consistent or distinct results.

2) specific objectives: (1) Test the in vivo effects of castration on human luminal cancer subsets isolated from primary regenerated prostate tumors, (2) Test the in vivo growth capacity of human luminal cancer subsets isolated from primary clinical prostate tumors, (3) Test the in vivo effects of castration on human luminal cancer subsets isolated from primary clinical prostate tumors.

3) significant results or key outcomes: Early results indicate that the I/LP fraction from experimental tumors can generate new tumors more readily than the remaining cancer cells. More data will be collected as these experiments are ongoing. We are incorporating a new tissue-slice approach into Aim 1 in order to measure the number and percentage of I/LP cells in primary human prostate tumors before and after castration (see below).

4) other achievements: Methodologies for Tasks $2 / 3$ have been updated following our initial attempts. Low numbers of sorted cancer cells have difficulty surviving after transplantation. Other groups have also failed to consistently demonstrate tumor re-growth from dissociated cancer cells (DomingoDomenech et al, Cancer Cell 2012: tumors formed in only 4 out of 30 samples attempted). However, we have identified a methodology that will enable us to answer these questions of whether I/LP cells preferentially survive androgen-deprivation. We are utilizing a tissue-slice approach reported by Donna Peehl's group whereby pieces of intact human prostate cancer tissue can be implanted under the renal capsule of immunodeficient intact or castrated mice (Zhao et al, Am J Pathol 2010). Analysis of tissues from intact/castrated mice will enable the proposed measurements and determination if $\mathrm{I} / \mathrm{LP}$ cells are enriched in castration-resistant tissue.

\section{Specific Aim 2. Proof of principle therapeutic targeting of I/LP cells to prevent CRPC.}

1) major activities: I/LP and remaining luminal cells from primary patient tissue have been analyzed at the RNA and protein levels. Early results indicate elevated NFkB signaling in I/LP cells leading us to inhibit this pathway and demonstrate a functional role for NFkB signaling and elF4E-driven protein translation in I/LP cell growth and survival.

2) specific objectives: (1) Determine if I/LP cancer cells from primary clinical human prostate tumors express genes associated with CRPC. (2) Determine regulators of I/LP clonogenic activity in vitro. (3) Target I/LP cells in vivo.

3) significant results or key outcomes: Preliminary analysis identifies

Fig 1. I/LP cells exhibit elevated NFkB

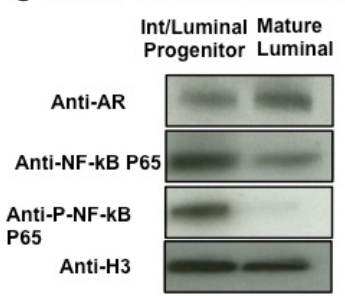

Western blot of I/LP and nonprogenitor mature luminal fractions from primary tumors stained for AR, NFkB (total and phosphorylated forms of p65) and Histone $\mathrm{H} 3$ (loading control)

NFkB activation increased in I/LP cells compared to luminal cells (Figure 1). These findings suggest that I/LP cells may rely on NFkB signaling for survival and growth.

As reported in our recent PNAS paper, human prostate AR-low luminal progenitor cancer cells driven by oncogenes Myc and myrAKT are dependent on protein translation factor elF4E and inhibition of this pathway prevents cell survival and clonogenicity (PNAS study attached, see Figure 6). 
Based on initial findings in Task 4 , we have tested in vitro growth of I/LP cells in the presence or absence of an NFkB inhibitor called ACHP. Clonogenic assays reveal a dramatic inhibition of growth (Figure 2).

We found that NFkB inhibition in I/LP cells is sufficient to reduce NFkB activation (p65 phosphorylation) and suppress expression of NFkB targets TNFR1 and BCL2 by western blot (Figure 3).

Mechanistically, we have found that NFkB inhibition causes reduction in elF4E, which we know is an important growth regulator and has been shown to be a transcriptional target of NFkB (Fig 3).
Fig 2. NFkB inhibition suppresses I/LP cell growth in a dose-dependent manner

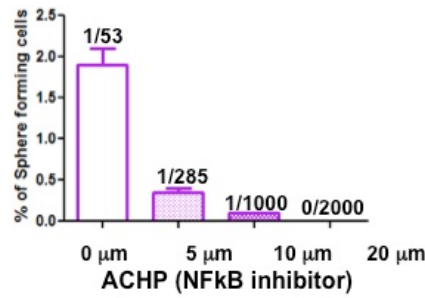

Results of a sphere assay using primary I/ LP cells in the presence of varying doses of the NFkB inhibitor ACHP added every 2 days. Spheres are counted 7-10 days post plating.
Growth defects caused by inhibition of NFkB can be partially rescued by over-expression of elF4E (Figure 4). These results suggest that we have identified two regulators of I/LP growth, NFkB signaling and eIF4E, which may be part of the same growth-promoting pathway.

4) other achievements: Nothing to Report

\section{Specific Aim 3. Diagnostic potential of I/LP cells as lurker cells to predict CRPC development.}

1) major activities: The gene signature of I/LP and nonprogenitor luminal cells was used to stratify patient outcome in a Watchful Waiting cohort to determine if I/LP transcriptional signature has predictive power.

2) specific objectives: (1) Determine whether I/LP cell transcriptional signature can predict patient prognosis.

(2) Testing of candidate I/LP biomarkers on prostate cancer tissue. (3) Determine if I/LP biomarkers can predict hormone sensitivity.

3) significant results or key outcomes: 281 men with prostate cancer were followed for 30 years in a Swedish watchful waiting cohort (Sboner et al, BMC Medical Genomics 2010). Preliminary data from this cohort suggests that the I/LP signature is associated with worse overall survival compared to the nonprogenitor luminal cell signature (Figure 5).

4) other achievements: Nothing to Report
Fig 3. NFkB inhibition suppresses expression of elF4E

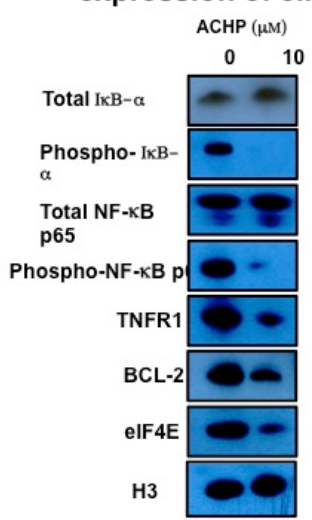

Western blot of I/LP spheres treated with $10 \mu \mathrm{m}$ NFkB inhibitor ACHP stained for total and phsophorylated IkB-a and p65. NFkB targets and survival/growth promoters TNFR1, BCL2 and elF4E are suppressed after treatment. Histone $\mathrm{H} 3$ is a loading control.

Fig 4. elF4E over-expression can partially rescue growth inhibition caused by NFkB blockade

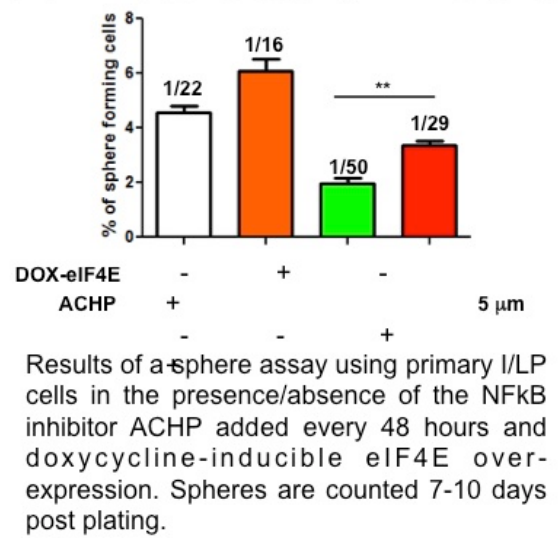

Fig 5. I/LP signature predicts worse survival

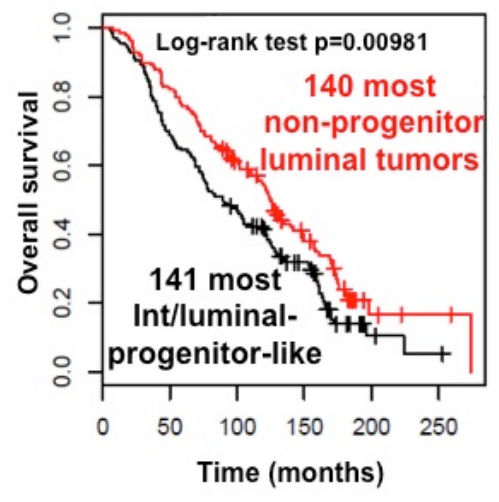


What opportunities for training and professional development has the project provided? The Principal Investigator was invited to participate and present data at the Prostate Cancer Foundation's Coffey-Holden Prostate Cancer Academy in June 2014 focused on "beyond immune therapy..."

How were the results disseminated to communities of interest?

Nothing to Report

What do you plan to do during the next reporting period to accomplish the goals?

Describe briefly what you plan to do during the next reporting period to accomplish the goals and objectives.

\section{IMPACT}

What was the impact on the development of the principal discipline(s) of the project?

Nothing significant to report as experiments are still ongoing and results need to be verified in larger cohorts. Our findings do point to a role for inflammatory signaling in progenitor-like cancer cells, which may represent a new therapeutic target or at least provide additional evidence to support this pathway as a target in advanced cancer.

What was the impact on other disciplines?

Nothing to Report

What was the impact on technology transfer?

Nothing to Report

What was the impact on society beyond science and technology?

Nothing to Report

\section{CHANGES/PROBLEMS}

\section{Changes in approach and reasons for change}

As described above and previously reported (Domingo-Domenech et al, Cancer Cell 2012), low numbers of sorted primary cancer cells have difficulty surviving after transplantation. However, we have identified a methodology that will enable us to answer these questions of whether I/LP cells preferentially survive androgen-deprivation. We are utilizing a tissue-slice approach reported by Donna Peehl's group whereby pieces of intact human prostate cancer tissue can be implanted under the renal capsule of immunodeficient intact or castrated mice (Zhao et al, Am J Pathol 2010). Analysis of tissues from intact/castrated mice will enable the proposed measurements and determination if I/LP cells are enriched in castration-resistant tissue. This approach will complement our initial methodology described in Tasks $2 / 3$.

Actual or anticipated problems or delays and actions or plans to resolve them Nothing to Report

\section{Changes that had a significant impact on expenditures}

Nothing to Report

Significant changes in use or care of human subjects, vertebrate animals, biohazards, and/or select agents

Nothing to Report 
Significant changes in use or care of human subjects

Nothing to Report

Significant changes in use or care of vertebrate animals.

Nothing to Report

Significant changes in use of biohazards and/or select agents

Nothing to Report

\section{PRODUCTS}

Publications, conference papers, and presentations

Work describing the role of luminal progenitor-like cancer cells in prostate cancer propagation and a requirement for elF4E signaling in their cell survival was reported in a 2013 PNAS article. Newer data on the pathways expressed in these cells that was collected during the first year while receiving funds from this award was presented at a conference in San Diego, CA.

Journal publications.

Stoyanova T, Cooper AR, Drake JM, Liu X, Armstrong AJ, Pienta KJ, Zhang H, Kohn DB, Huang J, Witte ON, Goldstein AS. Prostate cancer originating in basal cells progresses to adenocarcinoma propagated by luminal-like cells. PNAS USA (2013), 110:20111-20116. Federal support was not acknowledged because the study was completed prior to the initiation of DOD funds.

Liu X, Goldstein AS. Inflammation promotes prostate differentiation. PNAS USA (2014), 111:1666-7. Funding was not acknowledged for this preview/summary article.

Books or other non-periodical, one-time publications.

Nothing to Report

\section{Other publications, conference papers, and presentations.}

The Principal Investigator Andrew Goldstein presented his work, "Epithelial progenitor cells and inflammation" during a plenary session (Game Changing Research from PCF High-Achieving Young Investigators) at the Prostate Cancer Foundation $20^{\text {th }}$ annual meeting in Washington, DC in October, 2013. The PI also presented his work, "Prostate epithelial heterogeneity and immune cell interactions" at the Prostate Cancer Foundation's Coffey-Holden Prostate Cancer Academy held in San Diego, CA in June, 2014.

Website(s) or other Internet site(s)

Nothing to Report

Technologies or techniques

Nothing to Report

Inventions, patent applications, and/or licenses

Nothing to Report

Other Products

Nothing to Report 


\section{PARTICIPANTS \& OTHER COLLABORATING ORGANIZATIONS}

What individuals have worked on the project?

Provide the following information for: (1) PDs/PIs; and (2) each person who has worked at least one person month per year on the project during the reporting period, regardless of the source of compensation (a person month equals approximately 160 hours of effort). If information is unchanged from a previous submission, provide the name only and indicate "no change."

Name: Andrew Goldstein

Project Role: PI

Nearest Person Month Worked: 3

Contribution to Project: Initiation of tumors in Aim 1, analysis of I/LP cells in Aim 2

Name: Xian Liu

Project Role: Technician/Staff Research Associate

Nearest Person Month Worked: 3

Contribution to Project: Initiation of tumors in Aim 1, analysis of I/LP cells in Aim 2

Name: Steve Horvath

Project Role: Co-investigator

Nearest Person Month Worked: 1

Contribution to Project: Statistical/predictive outcome analysis of I/LP signature in Aim 3

Has there been a change in the active other support of the PD/PI(s) or senior/key personnel since the last reporting period?

Nothing to Report

What other organizations were involved as partners?

Nothing to Report

\section{SPECIAL REPORTING REQUIREMENTS}

N/A

9. APPENDICES: See attached 2013 PNAS article. 


\title{
Prostate cancer originating in basal cells progresses to adenocarcinoma propagated by luminal-like cells
}

\author{
Tanya Stoyanova ${ }^{a}$, Aaron R. Cooper ${ }^{b}$, Justin M. Drakea, Xian Liu', Andrew J. Armstrongd, Kenneth J. Pienta ${ }^{\mathrm{e}}$, \\ Hong Zhang ${ }^{f}$, Donald B. Kohn ${ }^{a, g, h}$, Jiaoti Huang ${ }^{f, g, h}$, Owen N. Witte ${ }^{a, c, g, h, i, 1}$, and Andrew S. Goldstein ${ }^{c, g, h, j, 1}$

\begin{abstract}
${ }^{a}$ Microbiology, Immunology and Molecular Genetics, ${ }^{b}$ Molecular Biology Interdepartmental Ph.D. Program, ${ }^{c}$ Departments of Molecular and Medical Pharmacology, ${ }^{f}$ Pathology and Laboratory Medicine, ${ }^{9}$ Jonsson Comprehensive Cancer Center, David Geffen School of Medicine, ${ }^{\mathrm{h}}$ Eli and Edythe Broad Center of Regenerative Medicine and Stem Cell Research, 'Howard Hughes Medical Institute, and 'Department of Urology, University of California, Los Angeles, CA 90095; dDuke Cancer Institute, Duke University Medical Center, Durham, NC 27710; and 'Brady Urological Institute, The Johns Hopkins School of Medicine, Baltimore, MD 21287
\end{abstract}

Contributed by Owen N. Witte, November 1, 2013 (sent for review October 18, 2013)

The relationship between the cells that initiate cancer and the cancer stem-like cells that propagate tumors has been poorly defined. In a human prostate tissue transformation model, basal cells expressing the oncogenes Myc and myristoylated AKT can initiate heterogeneous tumors. Tumors contain features of acinartype adenocarcinoma with elevated elF4E-driven protein translation and squamous cell carcinoma marked by activated betacatenin. Lentiviral integration site analysis revealed that alternative histological phenotypes can be clonally derived from a common cell of origin. In advanced disease, adenocarcinoma can be propagated by self-renewing tumor cells with an androgen receptor-low immature luminal phenotype in the absence of basal-like cells. These data indicate that advanced prostate adenocarcinoma initiated in basal cells can be maintained by luminal-like tumor-propagating cells. Determining the cells that maintain human prostate adenocarcinoma and the signaling pathways characterizing these tumor-propagating cells is critical for developing effective therapeutic strategies against this population.

$\mathbf{T}$ umors that arise from a given tissue in the body exhibit heterogeneity with respect to their molecular alterations, biological behavior, and response to therapy (1). Such variation presents a serious challenge for clinical cancer management. In many organ sites, tumors have been classified into subtypes based on their molecular and histological features (2). Subtypes of cancer can reflect distinct states of differentiation within a given tissue, leading Visvader and coworkers to propose that different epithelial tumor subtypes can arise from transformation of distinct cells of origin with different developmental potential (3). Functional studies in the mouse mammary gland and mouse lung support this model $(4,5)$. However, there is limited functional evidence for such a mechanism in human epithelial cancer.

Several recent studies using mouse models have revealed that the same phenotypic cell that initiates cancer can be responsible for tumor maintenance or propagation. Lgr5+ intestinal stem cells can initiate and maintain murine intestinal adenomas $(6,7)$. In mouse models of skin cancer, hair follicle bulge stem cells can serve as target cells for transformation (8) and CD34+ cells resembling their normal bulge stem cell counterpart are capable of propagating the disease as a cancer stem cell population (9). Mouse models of breast cancer demonstrate that tumors can arise from the transformation of luminal cells (4), and recent studies using human tumor samples indicate that breast cancer can also be propagated by luminal-like cells (10). In most human epithelial cancers it has not been determined whether the cell types that give rise to cancer are also capable of maintaining advanced disease.

The predominant histological subtype of prostate cancer is acinar-type adenocarcinoma (11), with features of luminal secretory cells, rare neuroendocrine cells, and an absence of basal cells. A number of less common histological variants are found in prostate cancer, including small cell carcinoma and squamous cell carcinoma. Both of these variants are associated with poor prognosis, aggressive disease, and resistance to hormonal therapy (androgen deprivation and/or androgen receptor blockade) (11). Small-cell carcinoma is characterized by proliferating neuroendocrine cells and loss of p53 (12). Squamous cancers have features of basal cells and can occur either in the context of adenocarcinoma or alone as squamous cell carcinoma $(11,13,14)$. Based on their different phenotypes and response to hormonal therapy, different histological variants of prostate cancer are predicted to arise from distinct cells of origin (13).

The relationship between the cells that initiate and maintain human prostate adenocarcinoma is not known. Naïve human prostate basal cells can initiate acinar-type adenocarcinoma in response to oncogenic stimulation (15). Consistent with these findings, basal cells from the BPH-1 human prostate cell line can initiate human prostate cancer in response to combined estrogen and testosterone treatment (16). These collective data suggest that human prostate tumors may set aside a subset of basal cells within the tumor to ensure continuous production of malignant luminal-like cancer cells.

Human prostate cancer cells with a basal phenotype have been reported to produce luminal cancer progeny in vitro (17). Using cell lines that were originally derived from human prostate tumors, it was shown that basal cell marker CD44 enriched for tumorpropagating cells in the absence of differentiated luminal cell markers (18). A recent study demonstrates that advanced chemotherapy-resistant prostate cancer is maintained by cells lacking basal or luminal cytokeratins (19). No study has defined the role of basal or luminal-like cells isolated directly from primary human prostate cancer in tumor propagation.

In the present study, we use a tissue-regeneration model of human prostate cancer to determine whether the cells at the origin of prostate cancer are continually required to maintain the disease as tumor-propagating cells. Benign cell populations isolated from primary human prostate tissue were first tested for

\section{Significance}

This study determined that two histological phenotypes of cancer can arise from a common target cell. Whereas luminal cells are not efficient cells of origin, luminal-like tumor cells isolated from human prostate adenocarcinoma can serially propagate advanced disease.

Author contributions: T.S., A.R.C., D.B.K., J.H., O.N.W., and A.S.G. designed research; T.S., A.R.C., J.M.D., X.L., H.Z., and A.S.G. performed research; A.J.A. and K.J.P. contributed new reagents/analytic tools; T.S., A.R.C., J.H., O.N.W., and A.S.G. analyzed data; and T.S., A.R.C., O.N.W., and A.S.G. wrote the paper.

The authors declare no conflict of interest.

Freely available online through the PNAS open access option.

${ }^{1}$ To whom correspondence may be addressed. E-mail: owenwitte@mednet.ucla.edu or agoldstein@mednet.ucla.edu.

This article contains supporting information online at www.pnas.org/lookup/suppl/doi:10. 1073/pnas.1320565110/-/DCSupplemental. 
their susceptibility to transformation by defined oncogenes. In the resulting tumors, cancer cell populations were further transplanted to define the cells capable of propagating the disease. Tumors driven by expression of oncogenes Myc and myristoylated/activated AKT (myrAKT) initiating in basal cells exhibit features of both adenocarcinoma and squamous cell carcinoma with different signaling pathways characteristic of each histological pattern. eIF4E-driven protein translation pathway is elevated in adenocarcinoma, whereas activation of beta-catenin is associated with squamous differentiation in experimental and clinical human prostate cancer. Using lentiviral integration site analysis, we determined that alternative histological phenotypes of prostate cancer can arise from a clonal cell of origin. Adenocarcinoma can be serially propagated by cells with a luminal phenotype. Our results indicate that cancer initiated in basal cells can evolve to adenocarcinoma maintained by luminal-like cells.

\section{Results}

Basal Cells Initiate Heterogeneous Human Prostate Cancer. Two of the most common alterations identified in human prostate tumors are increased expression of Myc (20) and activation of AKT, typically via loss of PTEN (21). Coexpression of Myc and phosphorylated AKT are rarely observed in primary localized prostate cancer, but are commonly found in advanced metastatic prostate tumors (Fig. 1A). The oncogenes Myc, myrAKT, or both Myc and myrAKT were introduced via lentivirus into highly enriched populations of human prostate basal $\left(\mathrm{CD} 45^{-}\right.$Trop2 $\left.2^{+} \mathrm{CD} 49 \mathrm{f}^{\text {hi }} \mathrm{CD} 26^{-}\right)$ and luminal $\left(\mathrm{CD} 45^{-}\right.$Trop $\left.2^{+} \mathrm{CD} 49 \mathrm{f}^{\text {lo }} \mathrm{CD} 26^{+}\right)$cells isolated by FACS. Basal and luminal epithelial cells were purified from preparations of dissociated, freshly isolated prostate tissue from six patients

A

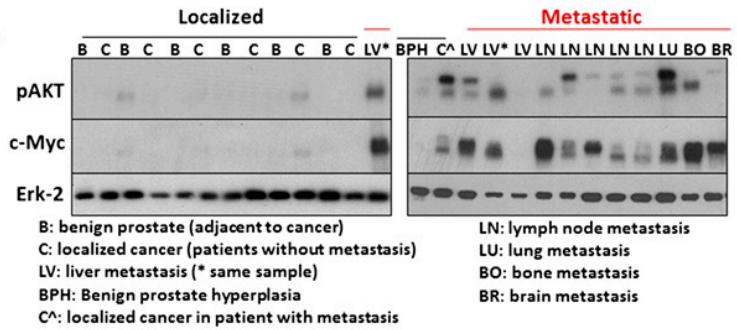

B

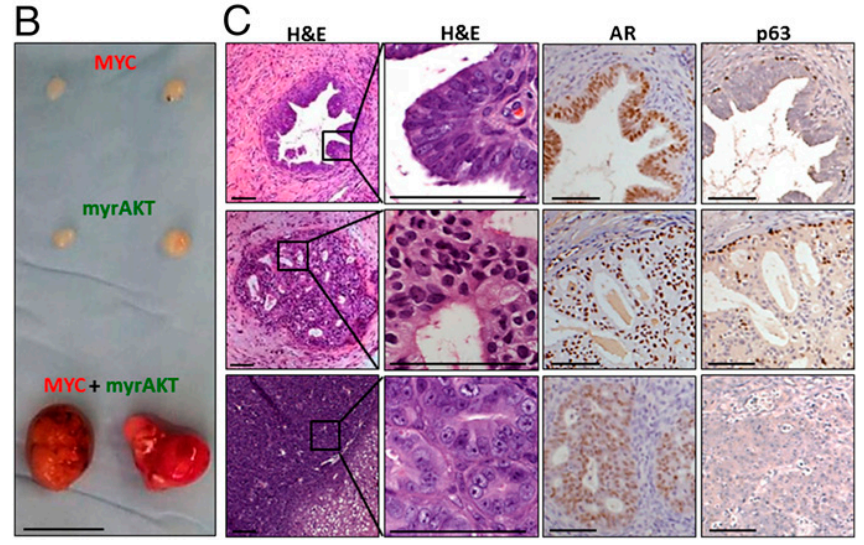

Fig. 1. Myc and myrAKT are coexpressed in advanced prostate cancer and synergize to initiate human prostate cancer. $(A)$ Localized (black line) and metastatic (red line) human prostate cancer specimens were subjected to Western blot analysis with antibodies against phosphorylated AKT (pAKT), Myc, and Erk as a loading control. (B) Naïve benign basal or luminal cells were transduced with Myc, myrAKT, or both Myc and myrAKT at varying cell doses. Representative tumors initiated from basal cells expressing Myc, myrAKT, or both after $8 \mathrm{wk}$ of regeneration. (Scale bar, $1 \mathrm{~cm}$.) (C) Histology of representative lesions initiated from basal cells expressing Myc, myrAKT, or both stained for H\&E, AR, and p63. (Scale bars, $100 \mu \mathrm{m}$.) undergoing radical prostatectomy. Transduced human prostate epithelial cells were combined with inductive murine urogenital sinus mesenchyme (UGSM) with Matrigel and implanted s.c. into immune-deficient NOD-SCID-IL2R $\gamma^{\text {null }}$ mice (Fig. S1A). Consistent with previous findings (15), infection of human prostate luminal-enriched cells did not result in any detectable epithelial structures after $12 \mathrm{wk}$ in vivo, regardless of whether cells were transduced with a single oncogene or the combination of Myc and myrAKT. Even implantation of 100,000 luminal cells was insufficient to generate primary tumors (Fig. S1B).

When expressed in naïve human prostate basal-enriched cells, Myc or myrAKT alone gave rise to benign glands or low-grade prostatic intraepithelial neoplasia lesions with distinct p63+ basal and androgen receptor-positive $(\mathrm{AR}+)$ luminal layers (Fig. $1 B$ and $C$ ). The two oncogenes dramatically synergized in human prostate basal cells to consistently generate large tumors in as little as 6 wk (Fig. 1B). Transduced basal cells were implanted in limiting numbers $\left(10^{5}, 5 \times 10^{4}, 10^{4}\right.$, and $\left.10^{3}\right)$ in vivo to determine the number of target cells required to respond to oncogenic stimulation. As few as 10,000 basal cells were sufficient to initiate tumors in $12 \mathrm{wk}$ (Fig. S1B). Metastasis was not observed in tumor-bearing mice, indicating that further genetic alterations or a longer time period may be required to observe metastatic lesions.

Regenerated tumors contained both acinar-type adenocarcinoma and squamous features (Fig. 2A). Adenocarcinoma regions were defined by high levels of expression of the luminal markers Keratin 8 (K8) and CD26, heterogeneous expression of AR, scattered chromogranin A+ neuroendocrine-like (NE) cells and an absence of basal markers Keratin 14 (K14), p63, and Keratin 5 (K5) (Fig. 2B). Conversely, squamous regions expressed basal cell markers $\mathrm{K} 14, \mathrm{p} 63$, and $\mathrm{K} 5$ and lacked cells expressing K8, CD26, AR, or chromogranin A. All tumors were confirmed to express oncogenes Myc and myrAKT and have a human origin based on staining with a pan-HLA antibody (Fig. $2 B$ and Fig. $\mathrm{S} 2$ ). This heterogeneous tumor provides a model to investigate the relationship between different histological phenotypes within an individual cancer. In clinical prostate cancer, the squamous phenotype is rare in primary tumors. Squamous differentiation is predominantly observed in aggressive metastatic tumors that are resistant to androgen-deprivation therapy (22).

Distinct Histological Phenotypes Share a Clonal Origin. Human prostate cancer often presents as a multifocal disease where distinct cancerous lesions are present within an individual patient's tissue. Multiple tumor foci can regularly be identified within regenerated tumors using the in vivo tissue-regeneration assay (15). We identified certain regions containing cells with adjacent squamous (K14/p63/K5) and luminal (K8/CD26) phenotypes in close proximity without defined borders (Fig. $3 A$ and $B$ ). These mixed regions made up an average of six foci per tumor, covering $\sim 18 \%$ of the total tumor area (Fig. S3). These regions containing both histological phenotypes originate either from the merging of two neighboring glands of distinct histological phenotypes or from a single gland capable of multilineage differentiation. The most definitive method to distinguish these possible outcomes is lentiviral integration site analysis (23).

Tumors were initiated from naïve human prostate basal cells transduced with lentivirus, resulting in the integration of viral DNA into the genome of the target cell and all of its progeny. If both adenocarcinoma and squamous phenotypes within an individual region arise from the same transformed basal cell, they should share a set of common lentiviral integration sites. However, if distinct histological phenotypes in an individual region arise from distinct cells of origin, they should not share any common integration sites.

Laser capture microdissection was performed on neighboring adenocarcinoma and squamous phenotypes within an individual lesion (region $\mathrm{X}$ ) and DNA was isolated separately from 

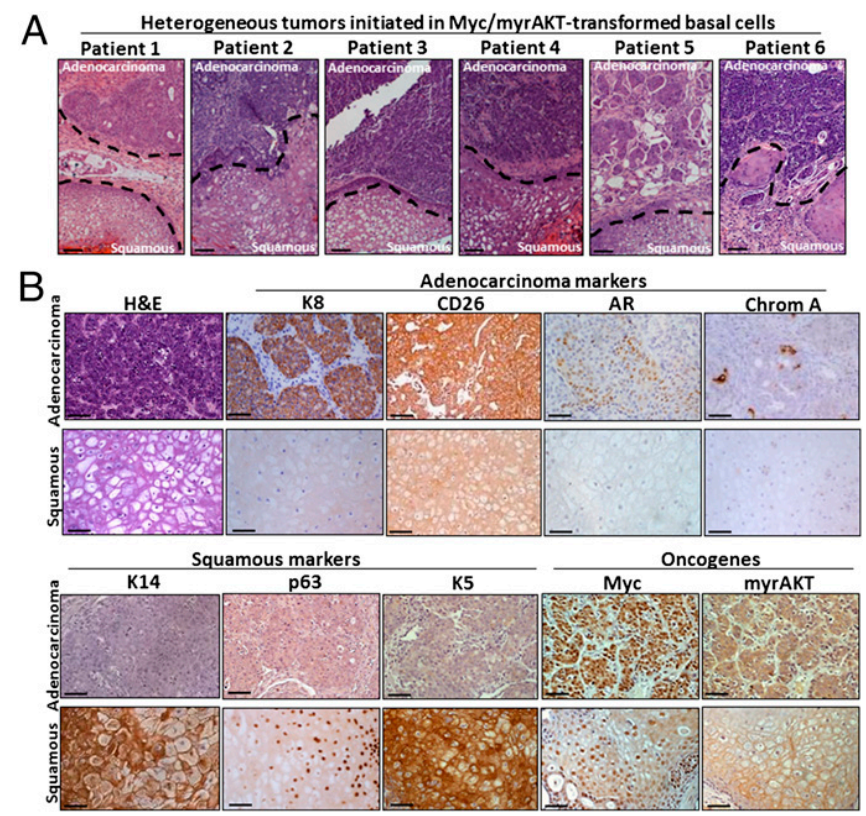

Fig. 2. Heterogeneous human prostate tumors containing squamous and acinar-type adenocarcinoma phenotypes. $(A) H \& E$ stains demonstrate heterogeneous tumors generated from the transformation of naïve benign basal cells from six distinct individuals. Dotted lines represent the borders of adenocarcinoma and squamous phenotypes. (Scale bars, $100 \mu \mathrm{m}$.) (B) Representative adenocarcinoma and squamous regions are identified based on staining for $\mathrm{H} \& \mathrm{E}$ and antibodies against luminal markers $K 8, C D 26$, and $A R$, the neuroendocrine marker chromogranin $\mathrm{A}$, and basal/squamous markers $\mathrm{K} 14$, p63, and $\mathrm{K} 5$, and oncogenes Myc and myrAKT/pAKT. (Scale bars, $100 \mu \mathrm{m}$.)

adenocarcinoma and squamous cells for lentiviral integration site analysis (Fig. 3B). DNA was also isolated from an individual lesion containing only the adenocarcinoma phenotype (region Y). In a distinct tumor, DNA was collected from neighboring adenocarcinoma and squamous phenotypes in close proximity (region Z). PCR primers specific for the viral DNA were used to extend into the genomic DNA (Fig. 3C). Illumina sequencing was performed and reads were aligned to the genome to map integration sites (Fig. 3C). Neighboring adenocarcinoma and squamous cells (region $\mathrm{X}$ ) shared common integration sites (Fig. $3 D$ and $E$ ), showing that they are derived from a clonal origin. In contrast, tissue taken from a distinct adenocarcinoma lesion (region Y) had entirely unique integration sites (Fig. $3 D$ and $E$ ). Common integration sites were also shared between neighboring adenocarcinoma and squamous phenotypes taken from a separate tumor (Region Z, Fig. $3 D$ and $E$ ). No overlapping integration sites were observed between different regions, as would be expected.

Beta-catenin signaling has been implicated in squamous differentiation and tumorigenesis in the prostate, mammary gland, and skin $(9,24,25)$. In human regenerated prostate tumors, the expression of total and activated forms of beta-catenin was evaluated in both adenocarcinoma and squamous tissues. In contrast to total beta-catenin, which is expressed in both histological variants, active beta-catenin is highly expressed in squamous areas (Fig. S4). Elevated Wnt signaling in the prostate microenvironment can transform adjacent naïve benign epithelium (26). Wnt ligands are elevated in prostate cancer stromal cells following treatment, leading to beta-catenin activation in the adjacent tumor cells (27). This is consistent with the presence of squamous differentiation in prostate cancer, which is rare in primary tumors but more commonly observed in late-stage prostate cancer following treatment $(14,22)$. High levels of activated beta-catenin could also be detected in clinical metastatic castration-resistant prostate cancer with squamous differentiation (Fig. S4).

Luminal-Like Cancer Cells Serially Propagate Adenocarcinoma in the Absence of Basal-Like Cells. Previous studies have established optimal conditions for tumorigenicity of dissociated human tumor cell preparations (28). Regenerated primary human prostate tumor cells initiated from the transformation of five distinct benign patient samples were dissociated to single cells. Human tumor cells were identified by FACS based on staining of a pan-HLA antibody (Fig. 4A). Luminal-like tumor cells were then isolated on the basis of low expression of CD49f and transplanted into secondary NSG mice.

Upon transplantation, isolated CD49f $\mathrm{f}^{\mathrm{lo}}$ tumor cells were capable of generating secondary tumors in recipient mice. Immunohistochemical staining on tumor-derived tissue sections identified a phenotype consistent with luminal/acinar-type adenocarcinoma (29) with a predominance of K8+ CD26+ luminal-like cells and an absence of K14+ p63+ basal-like cells (Fig. 4B). CD49f ${ }^{\text {lo }}$ tumor cells failed to regenerate the squamous phenotype. Secondary tumors derived from CD49f ${ }^{\text {lo }}$ cancer cells were almost entirely composed of a CD49f ${ }^{\text {lo }}$ Keratin $18+$ luminal-like phenotype as analyzed by flow cytometry (Fig. $5 A$ ) and expressed oncogenes Myc and myrAKT (Fig. S5). As few as $100 \mathrm{CD} 49 \mathrm{f}^{\text {lo }}$ cells taken from secondary tumors could generate tertiary tumors with a strictly adenocarcinoma phenotype (Fig. $5 B$ ). These data suggest that $\mathrm{CD} 49 \mathrm{f}^{\text {lo }}$ tumor cells can self-renew in a unipotent manner in vivo.

\section{A}
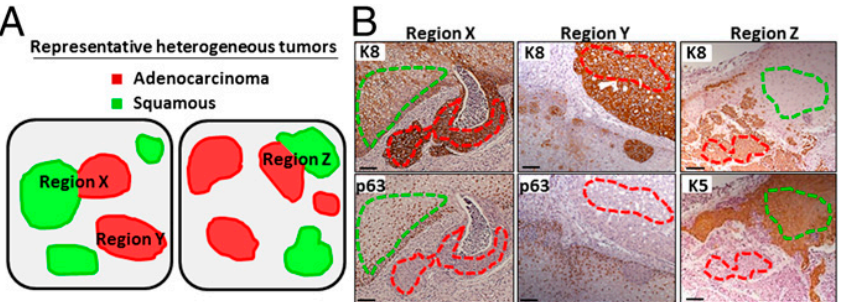

C
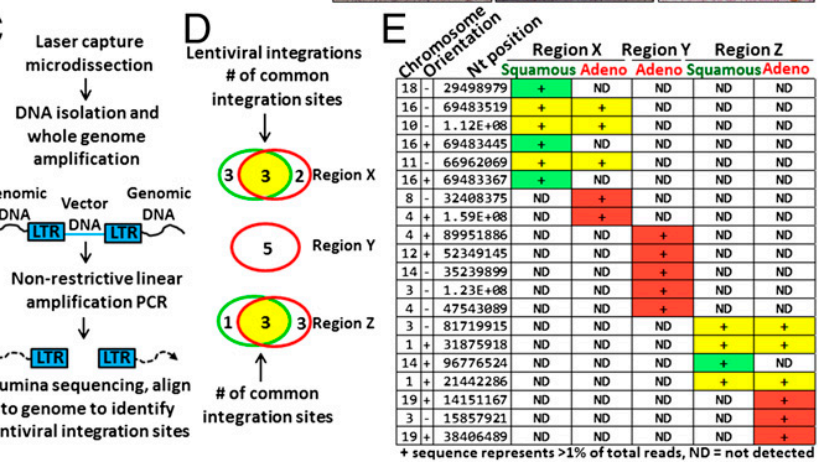

Fig. 3. Distinct histological variants in heterogeneous tumors can share a clonal origin. (A) Schematic of two different heterogeneous tumors containing adenocarcinoma, squamous, or both phenotypes. Regions $X, Y$, and $Z$. $(B)$ Representative regions $X, Y$, and $Z$ are shown with serial tissue sections stained with $\mathrm{K} 8$ to highlight adenocarcinoma and either p63 or $\mathrm{K} 5$ to highlight squamous regions. Dotted lines indicate region excised using laser capture microdissection. (Scale bars, $100 \mu \mathrm{m}$.) (C) Schematic of lentiviral integration site analysis. LTR, long terminal repeat (viral DNA). (D) Venn diagrams depict shared lentiviral integration sites in DNA isolated and amplified from neighboring adenocarcinoma (red) and squamous (green) phenotypes (region $\mathrm{X}$ ), distinct adenocarcinoma gland (region $\mathrm{Y}$ ), and additional neighboring adenocarcinoma and squamous phenotypes (region Z). (E) Table lists all unique integration sites (IS) with genomic location identifiers (chromosome, orientation, and nucleotide position) representing at least $1 \%$ of total reads (indicated by + ) in each sample. Rows in yellow represent shared IS between distinct histological phenotypes in the same region, rows in red indicate IS unique to adenocarcinoma, and green represent IS unique to squamous. 


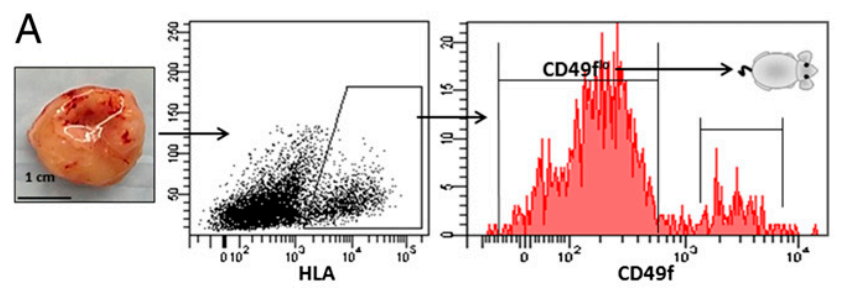

B

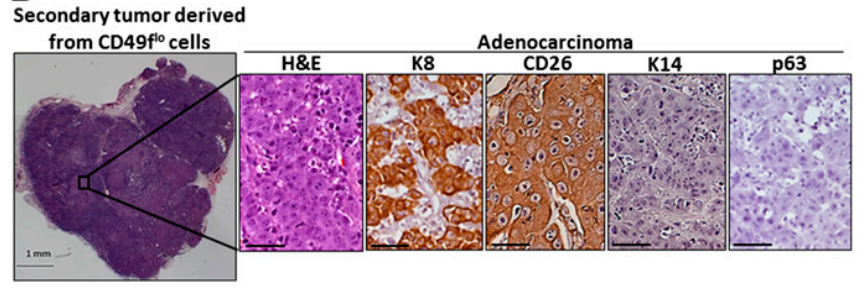

Fig. 4. Luminal-like cells isolated from primary tumors propagate adenocarcinoma. (A) Tumors initiated from CD49f $\mathrm{f}^{\mathrm{hi}}$ cells expressing Myc and myrAKT are dissociated to single cells and gated based on HLA+ and CD49f Isolated HLA+ CD49f ${ }^{\text {lo }}$ cells are transplanted back into recipient mice and harvested 6-12 wk later. (Scale bar, $1 \mathrm{~cm}$.) (B) H\&E-stained overview of a representative secondary tumor generated from 10,000 isolated CD49f ${ }^{10}$ tumor cells. Only the adenocarcinoma phenotype is observed as evidenced by stains for $\mathrm{H} \& \mathrm{E}, \mathrm{K} 8, \mathrm{CD} 26, \mathrm{~K} 14$, and p63. (Scale bars, $50 \mu \mathrm{m}$.)

CD49f $\mathrm{f}^{\text {hi }}$ tumor cells were also tested in transplantation assays. We found that CD49f ${ }^{\text {hi }}$ tumor cells could regenerate secondary lesions exhibiting a mixture of squamous (K14+ p63+) and adenocarcinoma (K8+ CD26+) areas (Fig. S6) that both expressed Myc and myrAKT (Fig. S7). These data suggest the presence of multipotent cells in the $\mathrm{CD} 49 \mathrm{f}^{\text {hi }}$ fraction capable of propagating both squamous and adenocarcinoma phenotypes.

In numerous tissues, high expression of Myc is associated with a block in differentiation and reprogramming to pluripotency (30). In prostate epithelium, Myc overexpression has been shown to reduce levels of AR (31) and its target prostate-specific antigen (PSA) (32). We hypothesized that high levels of Myc in Myc/myrAKT-driven tumors might cause a block in differentiation, resulting in reduced levels of AR and PSA. In primary regenerated tumors, we found low and heterogeneous expression of AR with only rare PSA+ glands (Fig. $1 C$ and Fig. S8). Levels of AR and PSA were low in secondary and tertiary tumors upon serial transplantation (Fig. $5 C$ and Fig. S8). These results are consistent with recent studies demonstrating that low or negative levels of AR and PSA are associated with tumor-propagating cells in prostate cancer xenografts $(18,19,33,34)$. Low levels of AR and PSA are also characteristic of DU145 (35) and PC3 (36) aggressive metastatic prostate cancer cells. In fact, expression of PSA, characteristic of clinical acinar-type adenocarcinoma, is inversely correlated with patient survival (18).

Luminal-Like Cancer Cells Exhibit Elevated elF4E-Driven Protein Translation. Our findings demonstrate that whereas naïve benign luminal cells are not efficient cells of origin for prostate cancer, CD49f ${ }^{\text {lo }}$ tumor cells with a luminal phenotype can self-renew and maintain human prostate adenocarcinoma in the absence of CD49f ${ }^{\text {hi }}$ or K14+ p63+ basal-like cells. Signaling pathways that are absent in benign luminal cells may become expressed in malignant luminal cells and contribute to their capacity to selfrenew and initiate tumorigenesis. Two pathways implicated in prostate tumorigenesis are the MAPK pathway (37) and the JAK/STAT pathway (38). Myc and myrAKT-driven tumor cells exhibited low levels of phosphorylated Erk1/2, downstream of the MAPK pathway, and weak staining for phosphorylated STAT3, a readout of the JAK/STAT pathway (Fig. S9).
The protein translation factor eIF4E is downstream of the PI3K pathway and has been shown to cooperate with Myc in promoting cell growth and tumorigenesis (39). eIF4E is unable to promote translation when bound by 4EBP1. mTOR-mediated phosphorylation of 4EBP1 (p4EBP1) relieves this interaction and allows eIF4E-driven translation initiation. High levels of eIF4E and p4EBP1 are associated with poor prognosis in prostate cancer (40) and have been shown to drive tumor invasion (41).

Elevated levels of eIF4E, 4EBP1 and p4EBP1 were found in luminal-like tumor cells isolated from Myc and myrAKT-driven tumors but not in benign luminal cells or in neighboring squamous cells (Fig. $6 A$ and $B$ and Fig. S10). Luminal-like tumor cells also express MTA1 and Sox2 (Fig. $6 A$ and $B$ ), two targets of eIF4E translation associated with prostate cancer progression. The self-renewal regulator Sox 2 has been previously demonstrated to promote the proliferation of prostate cancer cells (42). eIF4E, p4EBP1, MTA1, and Sox2 were identified in subsets of benign basal cells but not benign luminal cells (Fig. $6 A$ ). These findings suggest that luminal-like tumor cells may acquire a limited set of self-renewal and cell-survival factors normally associated with stem-like basal cells to promote tumor propagation.

Luminal-like cancer cells were grown in vitro and treated with pharmacological inhibitors previously demonstrated to interfere with eIF4E-driven protein translation. mTOR-mediated phosphorylation of 4EBP1 can be prevented by treatment with Rapamycin, allowing nonphosphorylated 4EBP1 to bind and inhibit eIF4E. PP242 inhibits both mTORC1 and mTORC2 and has been previously demonstrated to deplete eIF4E-driven protein translation (43). Dasatinib is a Src family kinase inhibitor that does not alter 4EBP1 phosphorylation. We tested the effect of eIF4E-driven protein translation inhibition on luminal-like cancer cells isolated from Myc and myrAKT-driven tumors. Treatment with rapamycin and PP242, but not with Dasatinib, caused a reduction in MTA1 and Sox 2 protein levels and depleted sphere number and size in vitro (Fig. $6 C-E$ ).

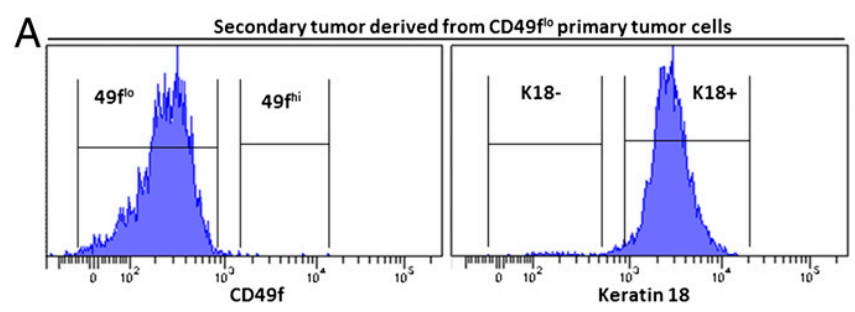

$B$
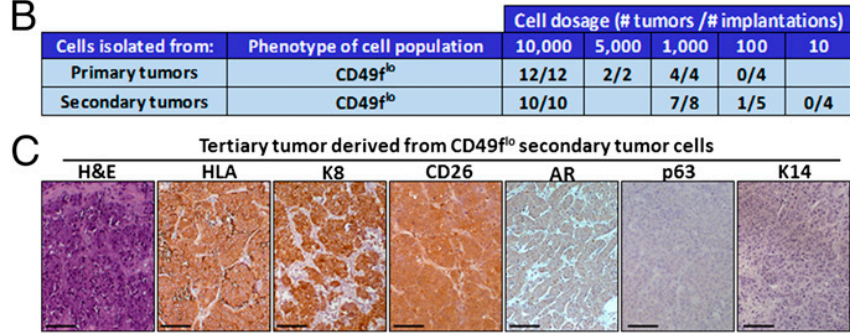

Fig. 5. Luminal-like tumor-propagating cells maintain human prostate adenocarcinoma in the absence of basal-like cells. $(A)$ Flow cytometry characterization of secondary tumors derived from CD49f ${ }^{\text {lo }}$ tumor cells. Secondary tumors derived from CD49f ${ }^{\mathrm{lo}}$ tumor cells were dissociated to single cells and stained for surface levels of CD49f or subjected to intracellular flow cytometry and stained for K18. (B) Table indicates number of tumors formed per transplantation of $\mathrm{CD} 49 \mathrm{f}^{\mathrm{lo}}$ cells (taken from either primary or secondary tumors) at varying cell doses. (C) CD49f ${ }^{\text {lo }}$ secondary tumor cells can generate tertiary tumors upon transplantation. Representative tertiary tumor sections are shown, stained for $H \& E$, the pan-human $H L A-A / B / C$ antibody, and markers of luminal adenocarcinoma (K8 and CD26) and basal cells (K14 and p63). (Scale bars, $100 \mu \mathrm{m}$.) 


\section{Discussion}

Epithelial cancers often exhibit significant heterogeneity at the histological level (1). By engineering expression of oncogenes or loss of tumor suppressors in specific lineages via cre-lox technology, it has been reported that different histological variants of mouse breast and lung cancer can arise from distinct cells of origin $(4,5)$. We have used a tissue-regeneration model to determine the origins of prostate cancer heterogeneity. Based on their distinct phenotypes and biological behaviors, histological variants of prostate cancer have been proposed to arise from different cells of origin (13). Myc- and myrAKT-initiated tumors exhibit features of both acinar-type adenocarcinoma and squamous cell carcinoma. Using lentiviral integration site analysis, we demonstrate that alternative human epithelial cancer phenotypes can arise from a common clonal target cell. Activated beta-catenin is elevated in areas with squamous differentiation both in experimental and clinical prostate cancer, suggesting a role for the beta-catenin pathway either in promoting or maintaining the squamous phenotype.

Our findings that basal cells are efficient cells of origin for human prostate cancer are consistent with previous findings by our group and others $(15,16)$. These studies on the human

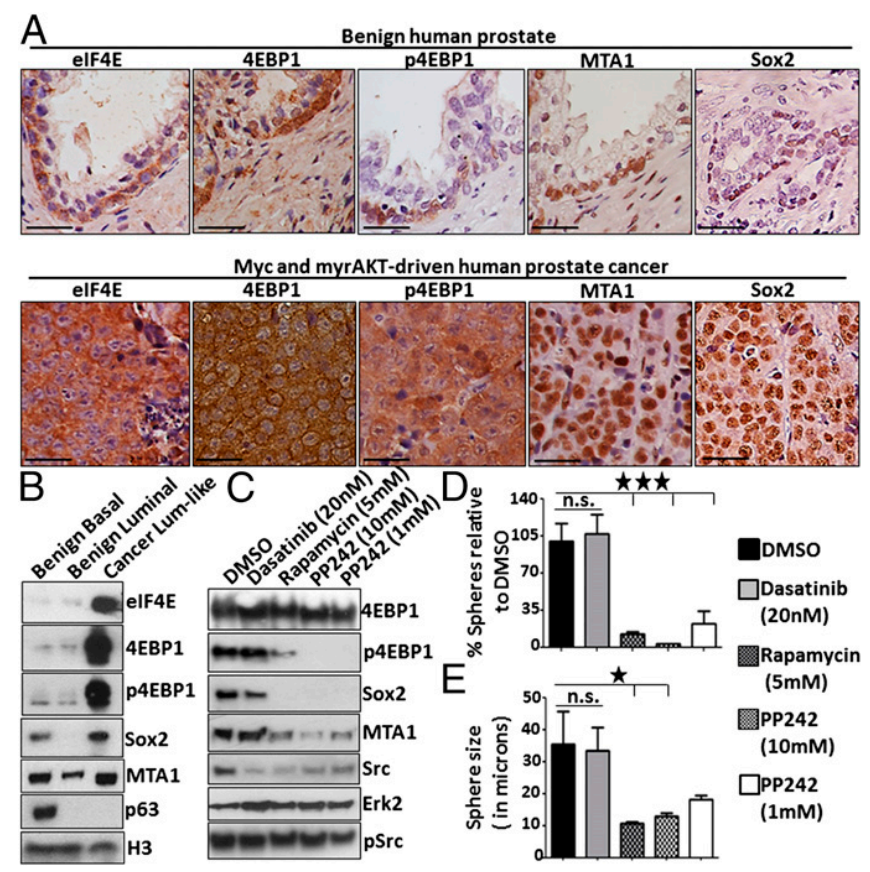

Fig. 6. Luminal-like tumor-propagating cells exhibit elevated elF4E-driven protein translation. (A) Immunohistochemical analysis of benign human prostate and primary tumors initiated by Myc and myrAKT stained for antibodies against elF4E, 4EBP1, phosphorylated 4EBP1 (Thr37/46), and the elF4E target MTA1. (Scale bars, $50 \mu \mathrm{m}$.) (B) Western blots of FACS-purified benign basal and luminal cells compared with luminal-like tumor cells stained with antibodies aginst elF4E, phosphorylated 4EBP1 (Thr37/46), 4EBP1, MTA1, Sox2, the basal marker p63, and loading control Histone H3. (C) Luminal-like cells isolated from Myc and myrAKT-driven tumors were treated with DMSO, Dasatinib, Rapamycin, and PP242 for $18 \mathrm{~h}$ followed by an additional treatment $1 \mathrm{~h}$ before harvesting. Lysates were subjected to Western blot for phosphorylated 4EBP1 (Thr37/46), Sox2, MTA1, total and phosphorylated Src (Y416), and Erk2 as a loading control. $(D)$ Luminal-like cells isolated from Myc- and myrAKTdriven tumors were plated into Matrigel and grown in a sphere assay. Cells were treated with DMSO, Dasatinib, Rapamycin, and PP242 every $48 \mathrm{~h}$ and sphere number and size was quantified after $10 \mathrm{~d}$ in vitro. Sphere number is presented as a percentage normalized to the DMSO control. (E) Sphere size is presented as the diameter in microns. Error bars represent SEM. Statistical analysis was performed using ANOVA and Newman-Keuls multiple comparison test. ${ }^{*} P<0.05, * * * P<0.0005$. n.s., not statistically significant.

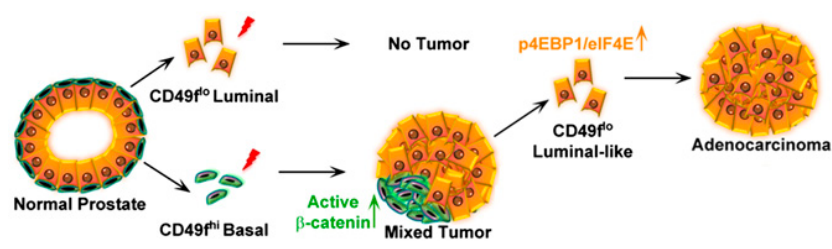

Fig. 7. Model of human prostate cancer initiation and propagation by distinct phenotypic cell populations.

disease have all used a tissue-regeneration approach to model development concomitant with tumorigenesis. Several different groups have investigated the origins of murine prostate cancer using genetically engineered mouse models in which the tumor suppressor Pten is deleted in a subset of basal or luminal cells from a young age. Depending on the genetic background of the mouse and the frequency of Pten deletion by the promoters used, there is considerable disagreement on whether basal or luminal cells generate a more proliferative, aggressive tumor that can model lethal human prostate cancer (44-46). Regardless of the assay system, studies using both mouse and human tissue confirm that transformed basal cells can generate malignant luminal progeny in vivo.

In the present study, we find that human prostate adenocarcinoma initiated by transformed basal cells can be propagated by phenotypically luminal cancer cells (Fig. 7). Such a model resembles chronic myelogenous leukemia (CML). CML is initiated in transformed hematopoietic stem cells $(47,48)$. Advanced disease can be maintained by granulocyte-macrophage progenitorlike cells that have gained self-renewal (49-51).

Several regulators of growth and self-renewal normally restricted to the stem-like basal cell compartment are likely to be expressed in malignant luminal cells in human prostate cancer and cooperate to promote their tumorigenic activity. In Myc- and myrAKT-driven human prostate tumors, luminal-like cancer cells exhibit elevated levels of p4EBP1 and eIF4E. Luminal-like tumor cells express MTA1 and Sox2, two targets of eIF4E-driven protein translation that are normally expressed in self-renewing basal cells but not benign luminal cells. These findings suggest that eIF4E-driven protein translation may contribute to luminallike tumor-propagating cell survival and self-renewal. In fact, activation of eIF4E downstream of Pten deletion in murine models of prostate cancer may play an important role in luminal cell transformation $(44,46)$.

\section{Methods}

Full methods, including antibodies, lentiviral vectors, laser capture microdissection, DNA isolation, and nonrestrictive linear amplification-mediated (nrLAM) PCR are found in SI Methods.

Human Tissue. Acquisition and processing of human tissue, dissociation and isolation of distinct epithelial subsets, lentiviral transduction, and in vivo implantation have all been described in detail (52). Patient tissue is provided in a de-identified manner and is exempt from institutional review board approval. Immunohistochemistry, Western blotting, and intracellular flow cytometry were performed as previously described (15).

Sequential Tumor Transplantation. Primary tumors were minced into small pieces, dissociated in $1 \mathrm{mg} / \mathrm{mL}$ type I collagenase (Invitrogen), $1 \mathrm{mg} / \mathrm{mL}$ Dispase (Invitrogen) and $50 \mu \mathrm{g} / \mathrm{mL}$ DNase I (Roche) at $37^{\circ} \mathrm{C}$ on an Adams Nutator Mixed (BD Biosciences) for $2-4 \mathrm{~h}$ and further digested with $0.05 \%$ trypsin/EDTA (Invitrogen) for $5 \mathrm{~min}$ at $37^{\circ} \mathrm{C}$ if necessary before sequential passing through $100-, 70-$, and $40-\mu \mathrm{m}$ cell strainers (BD Biosciences). Cells were stained with antibodies at $4{ }^{\circ} \mathrm{C}$ for $15-30 \mathrm{~min}$ and tumor cell populations were sorted on a BD FACS ARIA II into media with $50 \%$ (vol/vol) FBS (Omega Scientific). Isolated cells were counted by hemacytometer using trypan blue stain (Invitrogen), resuspended in $30 \mu \mathrm{L}$ Matrigel (BD Biosciences), and implanted s.c. into NOD-SCID-IL2R $\gamma^{\text {null }}$ (NSG) mice with or without UGSM cells. 
Animal Work. All primary, secondary, and tertiary tumors were transplanted s.c. into NOD-SCID-IL2R $\gamma^{\text {null }}$ (NSG) mice. NSG mice were originally purchased from the Jackson Laboratories and were housed and bred under the care of the Division of Laboratory Animal Medicine at the University of California, Los Angeles (UCLA). Surgical castration (orchiectomy) of tumor-bearing mice was performed according to protocols approved by UCLA's Animal Research Committee.

ACKNOWLEDGMENTS. We thank D. Cheng for cell sorting and the Tissue Procurement Core Laboratories for tissue preparation. Laser capture microdissection was performed at the California NanoSystems Institute Advanced Light Microscopy/Spectroscopy Shared Resource Facility at University of California, Los Angeles (UCLA), supported with funding from the Biosciences

1. Visvader JE (2011) Cells of origin in cancer. Nature 469(7330):314-322.

2. Perou $\mathrm{CM}$, et al. (2000) Molecular portraits of human breast tumours. Nature 406(6797):747-752.

3. Lim $\mathrm{E}$, et al.; $\mathrm{kConFab}$ (2009) Aberrant luminal progenitors as the candidate target population for basal tumor development in BRCA1 mutation carriers. Nat Med 15(8): 907-913.

4. Molyneux G, et al. (2010) BRCA1 basal-like breast cancers originate from lumina epithelial progenitors and not from basal stem cells. Cell Stem Cell 7(3):403-417.

5. Sutherland KD, et al. (2011) Cell of origin of small cell lung cancer: Inactivation of Trp53 and Rb1 in distinct cell types of adult mouse lung. Cancer Cell 19(6):754-764.

6. Barker N, et al. (2009) Crypt stem cells as the cells-of-origin of intestinal cancer. Nature 457(7229):608-611.

7. Schepers AG, et al. (2012) Lineage tracing reveals Lgr5+ stem cell activity in mouse intestinal adenomas. Science 337(6095):730-735.

8. Lapouge $\mathrm{G}$, et al. (2011) Identifying the cellular origin of squamous skin tumors. Proc Natl Acad Sci USA 108(18):7431-7436.

9. Malanchi I, et al. (2008) Cutaneous cancer stem cell maintenance is dependent on beta-catenin signalling. Nature 452(7187):650-653.

10. Kim J, et al. (2012) Tumor initiating but differentiated luminal-like breast cancer cells are highly invasive in the absence of basal-like activity. Proc Natl Acad Sci USA 109(16):6124-6129.

11. Humphrey PA (2012) Histological variants of prostatic carcinoma and their significance. Histopathology 60(1):59-74.

12. Chen $\mathrm{H}$, et al. (2012) Pathogenesis of prostatic small cell carcinoma involves the in activation of the P53 pathway. Endocr Relat Cancer 19(3):321-331.

13. Mott $L J$ (1979) Squamous cell carcinoma of the prostate: Report of 2 cases and review of the literature. J Urol 121(6):833-835.

14. Parwani AV, et al. (2004) Prostate carcinoma with squamous differentiation: an analysis of 33 cases. Am J Surg Pathol 28(5):651-657.

15. Goldstein AS, Huang J, Guo C, Garraway IP, Witte ON (2010) Identification of a cell of origin for human prostate cancer. Science 329(5991):568-571.

16. Taylor RA, et al.; Australian Prostate Cancer Bioresource (2012) Human epithelial basal cells are cells of origin of prostate cancer, independent of CD133 status. Stem Cells 30(6):1087-1096.

17. Collins AT, Berry PA, Hyde C, Stower MJ, Maitland NJ (2005) Prospective identification of tumorigenic prostate cancer stem cells. Cancer Res 65(23):10946-10951.

18. Qin J, et al. (2012) The PSA(-/lo) prostate cancer cell population harbors self-renewing long-term tumor-propagating cells that resist castration. Cell Stem Cell 10(5):556-569.

19. Domingo-Domenech J, et al. (2012) Suppression of acquired docetaxel resistance in prostate cancer through depletion of notch- and hedgehog-dependent tumor-initiating cells. Cancer Cell 22(3):373-388.

20. Gurel B, et al. (2008) Nuclear MYC protein overexpression is an early alteration in human prostate carcinogenesis. Mod Pathol 21(9):1156-1167.

21. Wang S, et al. (2003) Prostate-specific deletion of the murine Pten tumor suppressor gene leads to metastatic prostate cancer. Cancer Cell 4(3):209-221.

22. Rubin MA, et al. (2005) Effects of long-term finasteride treatment on prostate cancer morphology and clinical outcome. Urology 66(5):930-934.

23. Paruzynski A, et al. (2010) Genome-wide high-throughput integrome analyses by nrLAM-PCR and next-generation sequencing. Nat Protoc 5(8):1379-1395.

24. Bierie B, et al. (2003) Activation of beta-catenin in prostate epithelium induces hyperplasias and squamous transdifferentiation. Oncogene 22(25):3875-3887.

25. Miyoshi K, et al. (2002) Activation of beta -catenin signaling in differentiated mammary secretory cells induces transdifferentiation into epidermis and squamous metaplasias. Proc Natl Acad Sci USA 99(1):219-224.

26. Zong Y, et al. (2012) Stromal epigenetic dysregulation is sufficient to initiate mouse prostate cancer via paracrine Wht signaling. Proc Natl Acad Sci USA 109(50): E3395-E3404.

27. Sun $Y$, et al. (2012) Treatment-induced damage to the tumor microenvironment promotes prostate cancer therapy resistance through WNT16B. Nat Med 18(9): 1359-1368.
Core Facilities program at UCLA. T.S., J.M.D., and J.H. are supported by the Department of Defense Prostate Cancer Research Program. A.R.C. is supported by Ruth L. Kirschstein National Research Service Award GM007185. J.H. is supported by the UCLA Specialized Program of Research Excellence (SPORE) in prostate cancer (Prinicipal Investigator R. Reiter), a creativity award from the Prostate Cancer Foundation (PCF) (Principal Investigato M. Rettig) and National Institutes of Health Grant 1R01CA158627 (Principal Investigator L. Marks). A.S.G. is supported by the SPORE in Prostate Cancer (Principal Investigator R. Reiter) and a PCF Young Investigator Award. O.N.W is an Investigator of the Howard Hughes Medical Institute and is supported by the Eli and Edythe Broad Center of Regenerative Medicine and Stem Cell Research. A.S.G and O.N.W. are supported by a PCF Creativity Award (Principal Investigator O.N.W.). A.S.G, J.H., and O.N.W. are supported by a PCF Challenge Award (Principal Investigator O.N.W.)

28. Quintana $E$, et al. (2008) Efficient tumour formation by single human melanoma cells. Nature 456(7222):593-598.

29. van Leenders GJ, Aalders TW, Hulsbergen-van de Kaa CA, Ruiter DJ, Schalken JA (2001) Expression of basal cell keratins in human prostate cancer metastases and cell lines. J Pathol 195(5):563-570.

30. Leon J, Ferrandiz N, Acosta JC, Delgado MD (2009) Inhibition of cell differentiation: A critical mechanism for MYC-mediated carcinogenesis? Cell Cycle 8(8):1148-1157.

31. Ju X, et al. (2012) Novel oncogene induced metastatic prostate cancer cell lines define human prostate cancer progression signatures. Cancer Res 73(2):978-989.

32. Bernard D, Pourtier-Manzanedo A, Gil J, Beach DH (2003) Myc confers androgen-independent prostate cancer cell growth. J Clin Invest 112(11):1724-1731.

33. Maitland NJ, Frame FM, Polson ES, Lewis JL, Collins AT (2011) Prostate cancer stem cells: Do they have a basal or luminal phenotype? Horm Cancer 2(1):47-61.

34. Rajasekhar VK, Studer L, Gerald W, Socci ND, Scher HI (2011) Tumour-initiating stemlike cells in human prostate cancer exhibit increased NF-kappaB signalling. Nat Commun 2:162.

35. Chlenski A, Nakashiro K, Ketels KV, Korovaitseva GI, Oyasu R (2001) Androgen receptor expression in androgen-independent prostate cancer cell lines. Prostate 47(1): 66-75.

36. Kaighn ME, Narayan KS, Ohnuki Y, Lechner JF, Jones LW (1979) Establishment and characterization of a human prostatic carcinoma cell line (PC-3). Invest Urol 17(1): $16-23$

37. Mulholland DJ, et al. (2012) Pten loss and RAS/MAPK activation cooperate to promote EMT and metastasis initiated from prostate cancer stem/progenitor cells. Cancer Res 72(7):1878-1889.

38. Tam L, et al. (2007) Expression levels of the JAK/STAT pathway in the transition from hormone-sensitive to hormone-refractory prostate cancer. Br J Cancer 97(3):378-383.

39. Ruggero $D$, et al. (2004) The translation factor elF-4E promotes tumor formation and cooperates with c-Myc in lymphomagenesis. Nat Med 10(5):484-486.

40. Graff JR, et al. (2009) elF4E activation is commonly elevated in advanced human prostate cancers and significantly related to reduced patient survival. Cancer Res 69(9):3866-3873.

41. Hsieh AC, et al. (2012) The translational landscape of mTOR signalling steers cancer initiation and metastasis. Nature 485(7396):55-61.

42. Lin F, et al. (2012) Sox2 targets cyclinE, p27 and survivin to regulate androgen-independent human prostate cancer cell proliferation and apoptosis. Cell Prolif 45(3): 207-216

43. Feldman ME, et al. (2009) Active-site inhibitors of mTOR target rapamycin-resistant outputs of mTORC1 and mTORC2. PLOS Biol 7(2):e38.

44. Lu TL, et al. (2013) Conditionally ablated Pten in prostate basal cells promotes basalto-luminal differentiation and causes invasive prostate cancer in mice. Am J Pathol 182(3):975-991.

45. Wang ZA, et al. (2013) Lineage analysis of basal epithelial cells reveals their unexpected plasticity and supports a cell-of-origin model for prostate cancer heterogeneity. Nat Cell Biol 15(3):274-283

46. Choi N, Zhang B, Zhang L, Ittmann M, Xin L (2012) Adult murine prostate basal and luminal cells are self-sustained lineages that can both serve as targets for prostate cancer initiation. Cancer Cell 21(2):253-265.

47. Huntly BJ, et al. (2004) MOZ-TIF2, but not BCR-ABL, confers properties of leukemic stem cells to committed murine hematopoietic progenitors. Cancer Cell 6(6):587-596.

48. Passegué E, Wagner EF, Weissman IL (2004) JunB deficiency leads to a myeloproliferative disorder arising from hematopoietic stem cells. Cell 119(3):431-443.

49. Krivtsov AV, et al. (2006) Transformation from committed progenitor to leukaemia stem cell initiated by MLL-AF9. Nature 442(7104):818-822.

50. Jamieson $\mathrm{CH}$, Weissman IL, Passegué E (2004) Chronic versus acute myelogenous leukemia: A question of self-renewal. Cancer Cell 6(6):531-533.

51. Jamieson $\mathrm{CH}$, et al. (2004) Granulocyte-macrophage progenitors as candidate leukemic stem cells in blast-crisis CML. N Engl J Med 351(7):657-667.

52. Goldstein AS, et al. (2011) Purification and direct transformation of epithelial progenitor cells from primary human prostate. Nat Protoc 6(5):656-667. 


\section{Supporting Information}

\section{Stoyanova et al. 10.1073/pnas.1320565110}

\section{SI Methods}

Antibodies. Antibodies used for flow cytometry included CD49fPE, CD45-APCeFluor 780, HLA-A/B/C-biotin, StreptavidinAPC, and Streptavidin-APC-eFluor 780 (eBiosciences); CD49fAlexa Fluor 647 and CD26-FITC (BioLegend); and Trop2-APC (R\&D Systems). Antibodies used for immunohistochemistry and Western blot included Keratin 8 and Keratin 5 (Covance); Keratin 14 and HLA-A/B/C (Abcam); p63, Erk1/2, and androgen receptor (AR) (Santa Cruz); CD26/DPP4 (LifeSpan Biosciences); chromogranin A (Dako); Myc, eIF4E, and 4EBP1 (Epitomics); Histone H3, AKT, and p4EBP1 (Thr37/46); pErk1/ 2 (T202/Y204), pSTAT3 (Y705), Sox2, MTA1, Src, and pSrc (Y416) (Cell Signaling); beta-catenin (BD Biosciences); and active beta-catenin (Millipore).

Lentiviral Vectors. The myristoylated AKT vector was previously described (1). For cloning of the Myc vector, the pMX-humancMYC plasmid was purchased from Addgene (17966), cut with NotI, and blunted using Pfu polymerase. EcoRI linkers (Gene Link) were added to the $3^{\prime}$ end (former NotI site) by overnight blunt-end ligation using T4 DNA ligase (New England Biolabs). EcoRI was used to cut and release the MYC insert. The insert was gel-purified and cloned into the EcoRI sites of FU-CRW lentiviral backbone (2). Insert orientation was checked by ClaI digest and sequenced for confirmation. The resulting plasmid is now described as FU-Myc-CRW with the construct design presented in Fig. S1.

Laser Capture Microdissection, DNA Isolation, and Nonrestrictive Linear Amplification-Mediated PCR. Paraffin-embedded tissues were prepared on PEN membrane slides (Leica) and stained for H\&E without a coverslip. Tissue corresponding to squamous and adenocarcinoma regions were isolated using the LMD7000 (Leica). Tissue was collected into a $100-\mu \mathrm{L}$ nuclease-free PCR tube (Ambion). DNA was isolated and whole genome amplification was performed using the REPLI-g FFPE kit (Qiagen). Amplified human genomic

1. Xin L, Lawson DA, Witte ON (2005) The Sca-1 cell surface marker enriches for a prostate-regenerating cell subpopulation that can initiate prostate tumorigenesis. Proc Natl Acad Sci USA 102(19):6942-6947.

2. Memarzadeh S, et al. (2007) Enhanced paracrine FGF10 expression promotes formation of multifocal prostate adenocarcinoma and an increase in epithelial androgen receptor. Cancer Cell 12(6):572-585.
DNA was quantitated against an absolute plasmid standard via probe-based real-time PCR using primers uc483-F (GCATGCTTCATTAACAGTGACC) and uc483-R (TTTAAAATCTGAATGCATGATAAGAATGG) and probe FAM-uc483 (FAMAGATCCCCAGCTCATCCGTGATTG-Iowa Black) (3). An estimated 100-5,000 genomic equivalents of amplified DNA was used to perform nonrestrictive linear amplification PCR (4). Briefly, 100 cycles of linear amplification were performed with primer HIV3linear (Biotin-AGTAGTGTGTGCCCGTCTGT). Linear reactions were purified using 1.5 volumes of AMPure XP beads (Beckman Genomics) and captured onto M-280 Streptavidin Dynabeads (Invitrogen Dynal). Captured ssDNA was ligated to read 2 linker (Phos-AGATCGGAAGAGCACACGTCTGAACTCCAGTCAC3C Spacer) using CircLigase II (Epicentre) in a $10 \mu \mathrm{L}$ reaction at $65^{\circ}$ for $2 \mathrm{~h}$. PCR was performed on these beads using primer HIV3right (AATGATACGGCGACCACCGAGATCTACACTGATCCCTCAGACCCTTTTAGTC) and an appropriate indexed reverse primer (CAAGCAGAAGACGGCATACGAGAT-indexGTGACTGGAGTTCAGACGTGT). PCR products were mixed and quantified by probe-based quantitative PCR and appropriate amounts were used to load Illumina v3 flow cells. Paired-end 50bp sequencing was performed on an IlluminaHiSEq. 2000 instrument using a custom read 1 primer (CCCTCAGACCCTTTTAGTCAGTGTGGAAAATCTCTAGCA). Reads were aligned to the hg19 build of the human genome with Bowtie (5) and alignments were condensed and annotated using custom Perl and Python scripts to locate vector integrations. Integration sites were considered present and significant in a sample if they represented at least $1 \%$ of total sequence read alignments.

Inhibitors. HLA+ CD49f ${ }^{\text {lo }}$ luminal-like cells were isolated from Myc and myrAKT-driven human prostate tumors by FACS. For drug treatment, Dasatinib $(20 \mathrm{nM})$, Rapamycin $(20 \mu \mathrm{M})$, and PP242 $(10 \mu \mathrm{M}$ or $1 \mu \mathrm{M})$ (all from Selleck Chemicals) or DMSO control (Sigma) were used.

3. Cooper AR, et al. (2011) Highly efficient large-scale lentiviral vector concentration by tandem tangential flow filtration. J Virol Methods 177(1):1-9.

4. Paruzynski A, et al. (2010) Genome-wide high-throughput integrome analyses by nrLAM-PCR and next-generation sequencing. Nat Protoc 5(8):1379-1395.

5. Langmead B, Trapnell C, Pop M, Salzberg SL (2009) Ultrafast and memory-efficient alignment of short DNA sequences to the human genome. Genome Biol 10(3):R25 
A

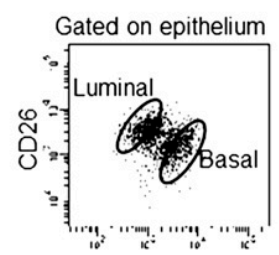

CD49f

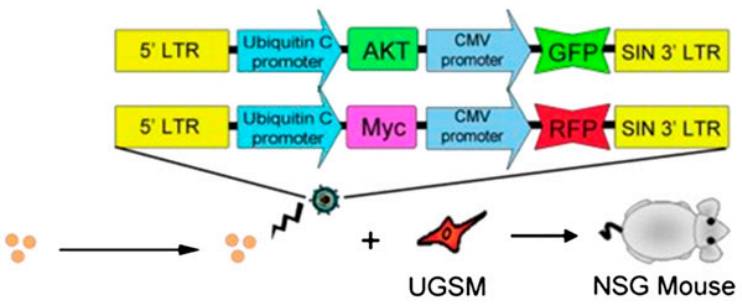

B Naive benign cells transduced with
Phenotype of cell population
Cell dosage (\# tumors /\# implantations)

\begin{tabular}{llll}
\hline 100,000 & 50,000 & 10,000 & 1,000
\end{tabular}

\begin{tabular}{|c|c|c|c|c|c|}
\hline Myc & $\begin{array}{l}\text { Basal (CD45- Trop2+ CD49f }{ }^{\text {hi }} \text { CD26-) } \\
\text { Luminal (CD45- Trop2+ CD49flo CD26*) }\end{array}$ & $\begin{array}{l}5 / 5 \\
0 / 5\end{array}$ & & & \\
\hline myrAKT & $\begin{array}{l}\text { Basal (CD45- Trop2+ CD49f }{ }^{\text {hi }} \text { CD26-) } \\
\text { Luminal (CD45- Trop2+ CD49flo CD26*) }\end{array}$ & $\begin{array}{l}5 / 5 \\
0 / 5\end{array}$ & & & \\
\hline Myc + myrAKT & $\begin{array}{l}\text { Basal (CD45- Trop2+ CD49fhi CD26-) } \\
\text { Luminal (CD45- Trop2+ CD49fio CD26*) }\end{array}$ & $\begin{array}{l}6 / 6 \\
0 / 6\end{array}$ & $\begin{array}{l}5 / 5 \\
0 / 5\end{array}$ & $2 / 4$ & $0 / 4$ \\
\hline
\end{tabular}

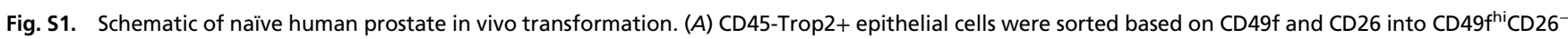
basal-enriched and $\mathrm{CD} 49 \mathrm{f}^{\mathrm{l}} \mathrm{CD} 26^{+}$luminal-enriched subsets, transduced with lentivirus carrying Myc, myristoylated/activated AKT (myrAKT), or both, combined with urogenital sinus mesenchyme cells and transplanted into NSG mice. $(B)$ The number of grafts recovered that contain epithelial lesions per number of grafts implanted in recipient mice is indicated. At doses of 100,000 or 50,000 transformed cells, a single graft was implanted from each patient sample representing five or six individuals. At lower cell doses, duplicate grafts were implanted from two individuals.
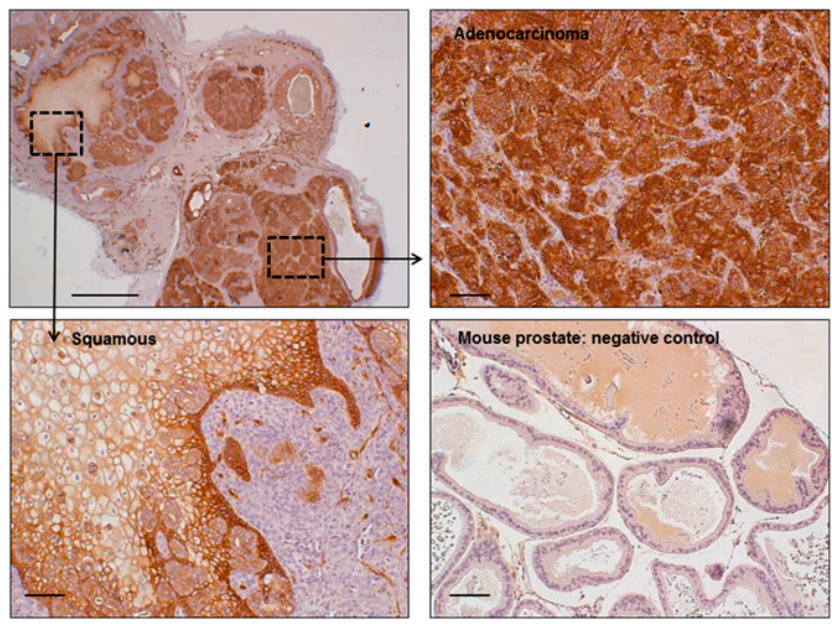

Fig. S2. Species-specific staining for HLA-A/B/C antibody. Tissue sections of human regenerated Myc/AKT tumors and mouse prostate tissue (negative control) were stained with a human-specific pan-HLA antibody to confirm species specificity. (Scale bars, $100 \mu \mathrm{m}$; top left overview, $1 \mathrm{~mm}$.)

\begin{tabular}{|c|c|c|c|c|c|c|}
\hline $\begin{array}{c}\text { Tumor } \\
\text { replicate }\end{array}$ & $\begin{array}{c}\text { \# glands } \\
\text { Adeno }\end{array}$ & $\begin{array}{c}\text { \# glands } \\
\text { Squamous }\end{array}$ & $\begin{array}{c}\text { \# glands } \\
\text { Mixed }\end{array}$ & $\begin{array}{l}\% \text { area } \\
\text { Adeno }\end{array}$ & $\begin{array}{c}\% \text { area } \\
\text { Squamous }\end{array}$ & $\begin{array}{l}\% \text { area } \\
\text { Mixed }\end{array}$ \\
\hline 1 & 1 & 3 & 0 & 65.4 & 34.6 & 0.0 \\
\hline 2 & 13 & 8 & 0 & 95.8 & 9.4 & 0.0 \\
\hline 3 & 5 & 12 & 13 & 4.0 & 44.4 & 51.6 \\
\hline 4 & 15 & 1 & 3 & 74.7 & 12.3 & 13.0 \\
\hline 5 & 1 & 11 & 5 & 5.8 & 84.4 & 9.9 \\
\hline 6 & 11 & 11 & 15 & 23.4 & 41.2 & 35.4 \\
\hline Average & 7.67 & 7.67 & 6 & 44.8 & 37.7 & 18.3 \\
\hline
\end{tabular}

Fig. S3. Quantification of stand-alone adenocarcinoma, stand-alone squamous, or mixed glands within regenerated tumors. Tissue sections representing Mycand myrAKT-initiated tumors were subjected to quantification of the number of glands and percentage of total tumor area harboring stand-alone adenocarcinoma, stand-alone squamous, or mixed glands. 


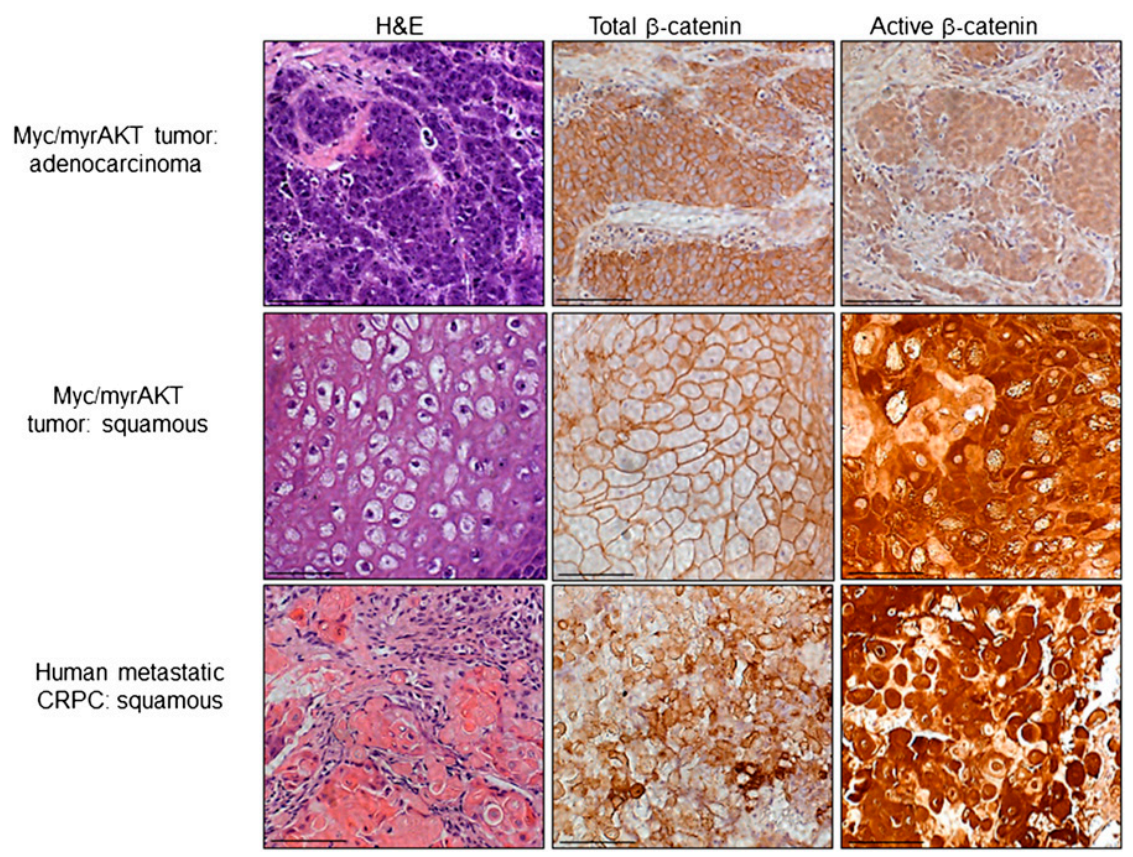

Fig. S4. Elevated expression of active beta-catenin in squamous cells. Representative adenocarcinoma and squamous regions from primary tumors driven by Myc and myrAKT, and a clinical metastatic castration-resistant prostate cancer (CRPC) sample with squamous differentiation were stained for H\&E and antibodies against total and activated beta-catenin. (Scale bars, $50 \mu \mathrm{m}$.)

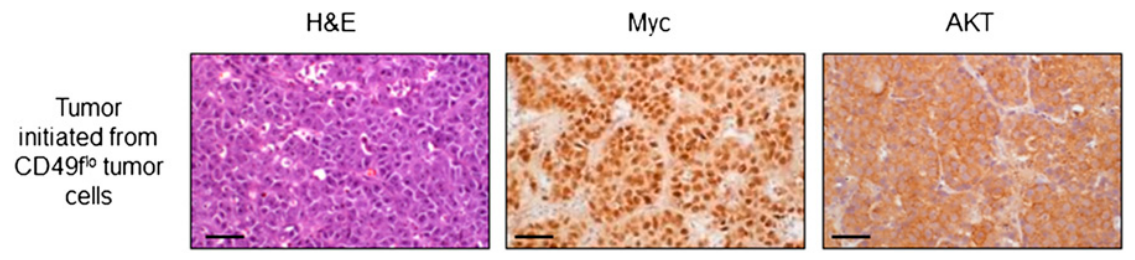

Fig. S5. Characterization of oncogene expression in histological variants present in secondary tumors initiated by CD49f $\mathrm{f}^{\mathrm{lo}}$ tumor cells. Secondary tumors were stained for $\mathrm{H} \& \mathrm{E}, \mathrm{Myc}$, and myrAKT and representative regions are shown. (Scale bars, $50 \mu \mathrm{m}$.)

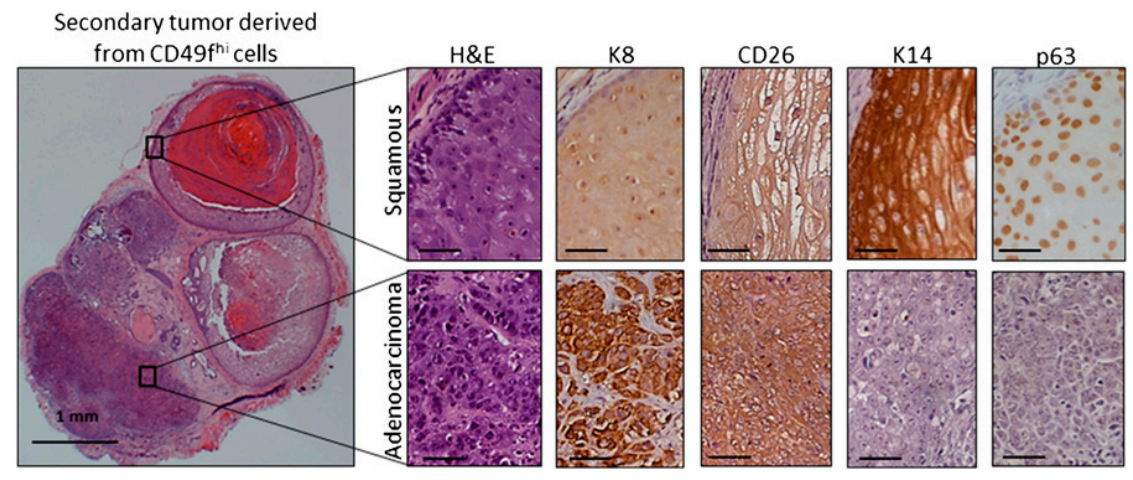

Fig. S6. Tumors initiated from CD49f $\mathrm{f}^{\text {hi }}$ cells expressing Myc and myrAKT were dissociated to single cells, gated based on HLA+, and CD49fhi tumor cells were transplanted back into recipient mice. H\&E-stained overview of a representative secondary tumor from 10,000 isolated CD49f ${ }^{\text {hi }}$ tumor cells after $6-12$ wk in vivo. Both squamous and adenocarcinoma phenotypes are represented in secondary tumors as distinguished by stains for H\&E, K8, CD26, $\mathrm{K} 14$, and p63. (Scale bars, $50 \mu \mathrm{m}$. 


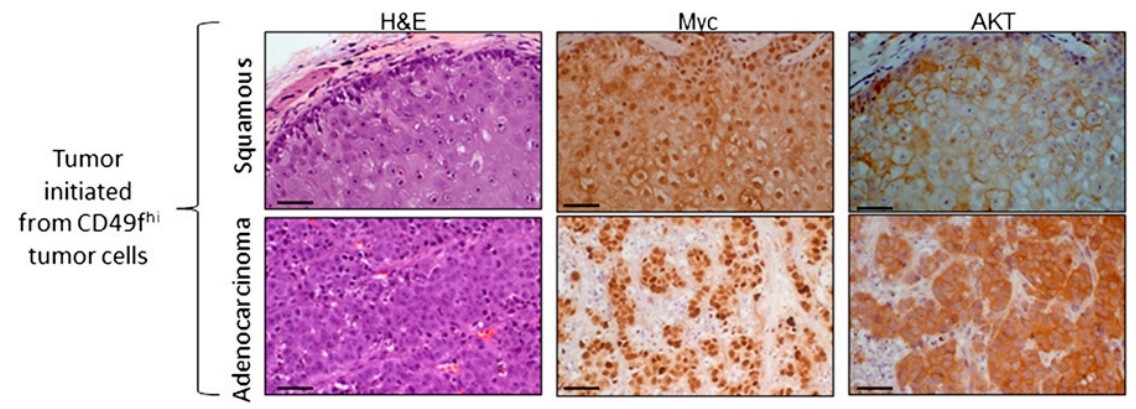

Fig. S7. Characterization of oncogene expression in histological variants present in secondary tumors initiated by CD49f ${ }^{\text {hi }}$ tumor cells. Primary tumors initiated in naïve benign CD49f ${ }^{\text {hi }}$ cells expressing Myc and myrAKT were dissociated to single cells. Isolated CD49f ${ }^{\text {hi }}$ tumor cells were transplanted into recipient mice to establish secondary tumors. Secondary tumors were stained for H\&E, Myc, and myrAKT and representative regions are shown. Regardless of the phenotype of secondary tumors, expression of oncogenes Myc and myrAKT was maintained. (Scale bars, $50 \mu \mathrm{m}$.)

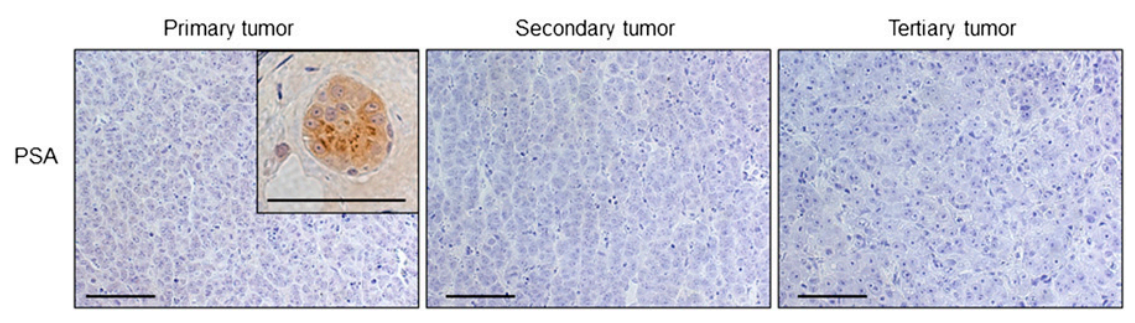

Fig. S8. Low or absent expression of prostate-specific antigen (PSA) in primary, secondary, and tertiary regenerated tumors. Immunohistochemical staining for $A R$ and PSA, a downstream target of AR signaling, in adenocarcinoma regions of regenerated tumors. Primary regenerated tumors, initiated in naïve benign CD49f ${ }^{\text {hi }}$ cells, show low or negative expression of PSA except for rare PSA+ glands (Inset). PSA expression is absent from secondary/tertiary tumors maintained by CD49f ${ }^{10}$ tumor cells. (Scale bars, $100 \mu \mathrm{m}$.)

A

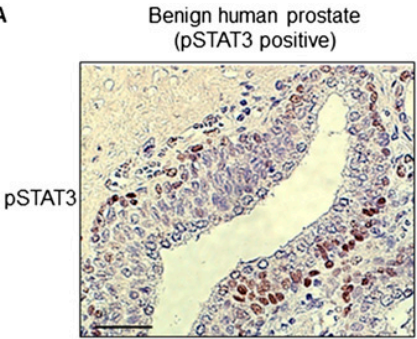

B

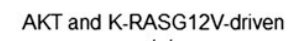

mouse prostate cancer

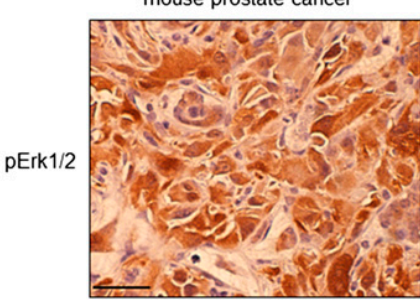

Benign human prostate (pSTAT3 negative)

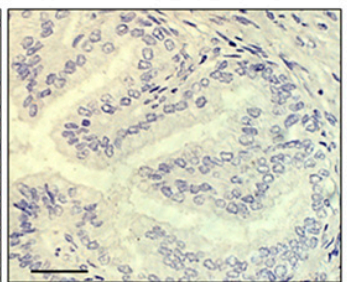

Benign human prostate

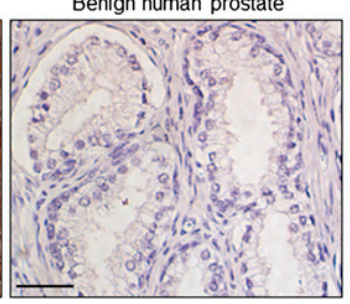

Myc and myrAKT-driven human prostate cancer

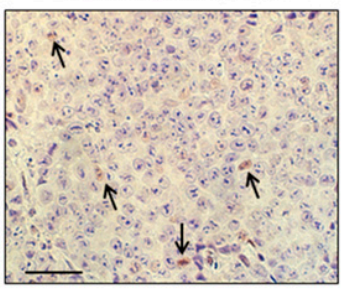

Myc and myrAKT-driven

human prostate cancer

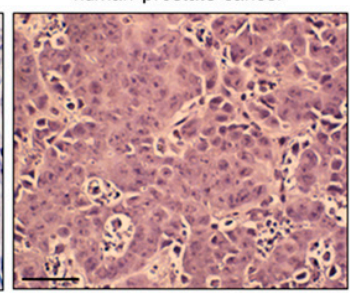

Fig. S9. Myc- and myrAKT-driven human prostate cancer exhibits low or absent expression pSTAT3 and pErk1/2 (A) Immunohistochemical staining for pSTAT3 ${ }^{Y 705}$ in benign human prostate and adenocarcinoma regions of regenerated Myc and myrAKT-driven tumors (arrows denote positive nuclei). ( $B$ ) Immunohistochemical staining for $\mathrm{pErk1/2} \mathrm{T}^{\mathrm{T} 202 / \mathrm{Y} 204}$ in AKT- and K-RAS $\mathrm{G}^{\mathrm{O} 2 \mathrm{~V}}$-driven mouse prostate cancer (positive control), benign human prostate and adenocarcinoma regions of regenerated Myc and myrAKT-driven tumors. (Scale bars, $50 \mu \mathrm{m}$.) 

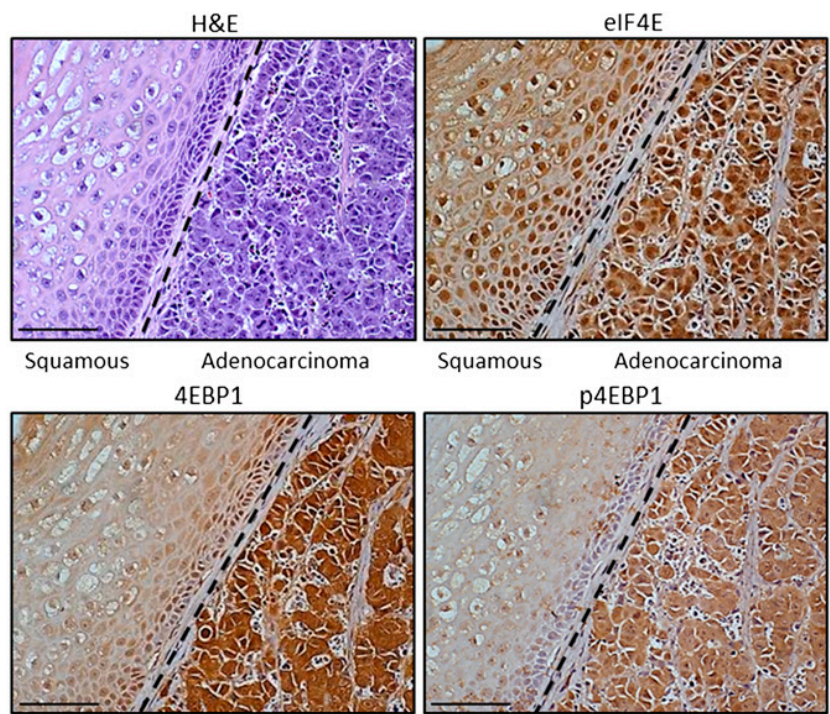

Squamous

Adenocarcinoma

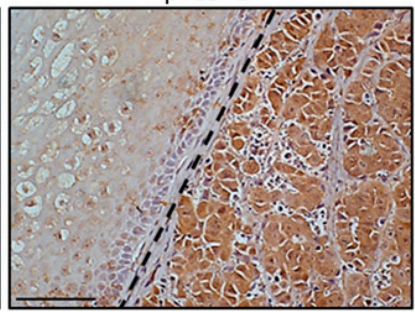

Squamous

Adenocarcinoma

Fig. S10. Expression of EIF4E/4EBP1 pathway components in adenocarcinoma and squamous cells. Immunohistochemical staining for H\&E, elF4E, total 4EBP1, and phosphorylated 4EBP1 (p4EBP1) in Myc/myrAKT-driven primary tumors indicates elevated pathway activation in adenocarcinoma cells compared with neighboring squamous cells. (Scale bars, $100 \mu \mathrm{m}$.) 